ARTICLE

\title{
Tumour suppressor death-associated protein kinase targets cytoplasmic HIF-1 $\alpha$ for Th17 suppression
}

Ting-Fang Chou ${ }^{1,2}$, Ya-Ting Chuang ${ }^{3}$, Wan-Chen Hsieh², Pei-Yun Chang ${ }^{2}$, Hsin-Yu Liu², Shu-Ting Mo², Tzu-Sheng Hsu², Shi-Chuen Miaw ${ }^{4}$, Ruey-Hwa Chen ${ }^{5,6}$, Adi Kimchi ${ }^{7}$ \& Ming-Zong Lai ${ }^{1,2,4}$

Death-associated protein kinase (DAPK) is a tumour suppressor. Here we show that DAPK also inhibits T helper 17 (Th17) and prevents Th17-mediated pathology in a mouse model of autoimmunity. We demonstrate that DAPK specifically downregulates hypoxia-inducible factor $1 \alpha(\mathrm{HIF}-1 \alpha)$. In contrast to the predominant nuclear localization of HIF-1 $\alpha$ in many cell types, HIF-1 $\alpha$ is located in both the cytoplasm and nucleus in T cells, allowing for a cytosolic DAPK-HIF-1 $\alpha$ interaction. DAPK also binds prolyl hydroxylase domain protein 2 (PHD2) and increases HIF-1 $\alpha$-PHD2 association. DAPK thereby promotes the proline hydroxylation and proteasome degradation of HIF- $1 \alpha$. Consequently, DAPK deficiency leads to excess HIF- $1 \alpha$ accumulation, enhanced IL-17 expression and exacerbated experimental autoimmune encephalomyelitis. Additional knockout of $\mathrm{HIF}-1 \alpha$ restores the normal differentiation of Dapk ${ }^{-/}$- Th17 cells and prevents experimental autoimmune encephalomyelitis development. Our results reveal a mechanism involving DAPK-mediated degradation of cytoplasmic HIF-1 $\alpha$, and suggest that raising DAPK levels could be used for treatment of Th17-associated inflammatory diseases.

\footnotetext{
${ }^{1}$ Graduate Institute of Life Sciences, National Defense Medical College, Taipei 11490, Taiwan. ${ }^{2}$ Institute of Molecular Biology, Academia Sinica, Taipei 11529, Taiwan. ${ }^{3}$ Department of Medical Research, National Taiwan University Hospital, Taipei 10002, Taiwan. ${ }^{4}$ Institute of Immunology, National Taiwan University, Taipei 10057, Taiwan. ${ }^{5}$ Institute of Biological Chemistry, Academia Sinica, Taipei 11529, Taiwan. ${ }^{6}$ Institute of Molecular Medicine, National Taiwan University, Taipei 10057, Taiwan. ${ }^{7}$ Department of Molecular Genetics, Weizmann Institute of Science, Rehovot 76100, Israel. Correspondence and requests for materials should be addressed to M.-Z.L. (email: mblai@gate.sinica.edu.tw).
} 
pon activation, the T helper 17 (Th17) subset of immune cells plays critical roles in modulating tissue inflammation and combating microbial infections. However, due to their inflammatory nature, Th17 cells also contribute to autoimmune diseases ${ }^{1-3}$. Experimental autoimmune encephalomyelitis (EAE) is a well-studied mouse model for multiple sclerosis that is also mediated by Th17 (refs 4-6). Th17 cells differ from the Th1 and Th2 lineages in secretion of interleukin (IL)-17 (refs 7,8 ), which induces inflammatory gene expression in target cells and leads to pathogenesis in the EAE model ${ }^{9}$. Transforming growth factor (TGF)- $\beta$ is critical for the commitment to the Th17 lineage ${ }^{10,11}$. TGF- $\beta$ acts synergistically with the STAT3-activating cytokines, IL-6, IL-21 and IL-23, to promote ROR $\gamma$ t expression and Th17 differentiation ${ }^{4,7,12-16}$. The Th17-specific transcription factor ROR $\gamma \mathrm{t}^{12}$ acts together with ROR $\alpha$ and STAT3 (ref. 17) to induce full Th17 cell differentiation.

Hypoxia-inducible factor- $1 \alpha$ (HIF- $1 \alpha$ ) is an oxygen tension sensor widely expressed in different cell types, including Th17 cells. In the presence of $\mathrm{O}_{2}, \mathrm{HIF}-1 \alpha$ is hydroxylated at Pro402 and Pro564 by prolyl hydroxylase domain protein 2 (PHD2)/PHD3, followed by ubiquitination by the von Hippel-Lindau (VHL)-containing E3 complex that promotes proteasome degradation ${ }^{18-22}$. At low oxygen tension, HIF-1 $\alpha$ is stabilized by inactivation of PHD2/PHD3 (refs 18-22). Once stabilized, HIF- $1 \alpha$ activates the expression of target genes involved in hypoxic responses. HIF- $1 \alpha$ is also upregulated by inflammatory cytokines in normoxic conditions ${ }^{23}$.

The Hifla transcript is constitutively expressed in T lymphocytes, and the HIF- $1 \alpha$ protein is detected after T-cell receptor (TCR) stimulation under hypoxic conditions ${ }^{24,25}$. HIF- $1 \alpha$ is highly expressed in Th17 cells ${ }^{26,27}$, priming at physiological oxygen tension in the presence of inflammatory cytokines. HIF- $1 \alpha$ plays a prominent role in Th17 cell differentiation ${ }^{26,27}$ by activating the transcription of $\operatorname{Rorc}(\mathrm{ROR} \gamma \mathrm{t})$, and it helps recruit $\mathrm{CBP} / \mathrm{p} 300$ to the $\mathrm{ROR} \gamma \mathrm{t}$ transcription complex but does not directly bind to the IL-17 promoter ${ }^{27}$. Additionally, HIF- $1 \alpha$ increases glycolysis by inducing the expression of glycolytic enzymes, which further contributes to Th17 development ${ }^{26,28}$. HIF- $1 \alpha$ also contributes to the survival of Th17 cells by coordination with Notch to enhance Bcl-2 expression ${ }^{29}$. In contrast, targeted degradation of HIF- $1 \alpha$ by miR-210 negatively regulates Th17 differentiation ${ }^{30}$.

HIF- $1 \alpha$ promotes carcinogenesis and is a prominent cancer target $^{18,19}$. Various HIF- $1 \alpha$ inhibitors have been identified and are currently being studied for their efficacy in cancer therapy $^{18,19,31,32}$. Presumably, HIF- $1 \alpha$ inhibitors could also be used for treatment of Th17-mediated inflammatory diseases. However, HIF- $1 \alpha$ is essential for oxygen homoeostasis, and curtailment of the protective effects of HIF- $1 \alpha$ by HIF- $1 \alpha$ inhibitors may limit their application.

Death-associated protein kinase (DAPk/DAPK) is a multidomain serine/threonine kinase regulated by calcium ${ }^{33,34}$. DAPK belongs to the DAPK family, which also contains DAPK-related protein 1 and zipper-interacting protein kinase (also called DAPK3), both of which share $80 \%$ identity in their kinase domains with $\mathrm{DAPK}^{33}$. The DAPK family also contains two distantly related kinases: DAPK-related apoptosis inducing kinase 1 and 2 (DRK1 and DRK2) ${ }^{35}$. DAPK family members are pro-apoptotic proteins and function as tumour suppressors, and are specifically downregulated in many types of cancer ${ }^{36-41}$. DAPK participates in a wide variety of cellular events-including apoptosis, autophagy, membrane blebbing and stress fibre formation-that contribute to its tumour suppressor functions. In T lymphocytes, DAPK inhibits T-cell activation by suppressing TCR-induced nuclear factor (NF)- $\mathrm{B}$ activation ${ }^{42}$. DAPK is induced by TGF- $\beta$ (ref. 43), and is present in the early precursors of Th17, but the role of DAPK in Th17 immune cells is unclear.

In the present study, we found that DAPK negatively regulates Th17 differentiation. DAPK deficiency leads to preferential Th17 differentiation and exacerbated EAE induction. During the differentiation of Th17, the presence of DAPK is accompanied by downregulation of HIF-1 $\alpha$. We further found that, in contrast to the exclusive nuclear localization of HIF- $1 \alpha$ in most other cells, HIF- $1 \alpha$ is located in both the cytoplasm and nucleus of T cells, allowing the cytosolic binding of DAPK and subsequent HIF- $1 \alpha$ degradation. Our results illustrate a novel mechanism of Th17 regulation by downregulating cytoplasmic HIF- $1 \alpha$, and suggest the therapeutic potential of increasing DAPK levels in Th17-mediated inflammatory diseases.

\section{Results}

DAPK inhibits T-cell activation and attenuates EAE. Our previous studies showed that expression of the dominant negative mutant of DAPK, [K42A]DAPK, leads to increased IL-2 production and NF- $\mathrm{B}$ activation in T-cell lines ${ }^{42}$. Extending these studies, we examined T cells from the Dapk ${ }^{-i-}$ mouse ${ }^{44}$. T-cell development was not affected by DAPK deficiency, as illustrated by the normal thymic and peripheral T-cell populations in the Dapk $k^{-1}$ mouse (Supplementary Fig. 1a,b). Following TCR stimulation, Dapk ${ }^{-/}$T-cell proliferation was enhanced relative to the wild-type (WT) T cells (Supplementary Fig. 2a). This was associated with increased IL-2 and interferon (IFN) $-\gamma$ production in naive Dapk ${ }^{-1-}$ T cells (Supplementary Fig. 2b). An increase in IL-17 was also observed in Dapk ${ }^{-1-}$ $\mathrm{T}$ cells (Supplementary Fig. 2c). In contrast, the production of IL-4 in primary $\mathrm{T}$ cells was not affected by DAPK deficiency (Supplementary Fig. 2c). Additionally, IFN- $\gamma$ production was similar between WT and Dapk ${ }^{-1-}$ T cells when cultured in Th0 conditions (Supplementary Fig. 2d). A prominent increase in $\mathrm{NF}-\kappa \mathrm{B}$ activation, indicated by the enhanced nuclear translocation of p65 (RelA), was also observed in Dapk $k^{-1-} \mathrm{T}$ cells stimulated through the TCR (Supplementary Fig. 2e).

We further examined whether the enhanced T-cell activation in Dapk ${ }^{-1-}$ mice led to increased susceptibility to autoimmune diseases, using EAE as our model. After priming with myelin oligodendrocyte glycoprotein (MOG) peptide, disease onset was earlier in Dapk $k^{-}-$mice than their WT littermates (Fig. 1a). Additionally, the severity of encephalomyelitis was higher in Dapk $k^{-1}$ mice than their WT counterparts. This was correlated with an increase in mononuclear cell infiltration and demyelination in spinal cords from primed Dapk ${ }^{-1-}$ mice (Fig. 1b,c). We also isolated $\mathrm{T}$ cells from the primed mice and determined their reactivity towards antigen. Consistent with exacerbated EAE generation, the response to MOG peptide in Dapk $k^{-1-} \mathrm{T}$ cells was nearly double that of control T cells (Fig. 1d).

We further used transgenic mice with T-cell-specific expression of $[\triangle \mathrm{CAM}] \mathrm{DAPK}{ }^{42}$, the constitutively active form of DAPK, to analyse EAE induction. T-cell development was normal in [ $\triangle \mathrm{CAM}] \mathrm{DAPK}$-transgenic mice (Supplementary Fig. 3a,b). We increased the dose of MOG peptide for a more profound EAE response in the control mice, allowing us to differentiate any inhibitory effect from the DAPK transgene. The expression of $[\triangle \mathrm{CAM}] \mathrm{DAPK}$ in $\mathrm{T}$ cells suppressed EAE generation (Supplementary Fig. 3c). The EAE symptoms were attenuated in $[\triangle \mathrm{CAM}] \mathrm{DAPK}$-transgenic mice in comparison with WT littermate controls. Reduced responses to MOG peptide were also found for $\mathrm{T}$ cells isolated from $[\triangle \mathrm{CAM}] \mathrm{DAPK}$-transgenic mice (Supplementary Fig. 3d). Together, these results demonstrate that DAPK deficiency enhanced EAE generation, whereas T-cellspecific expression of active DAPK suppressed EAE induction, 
a

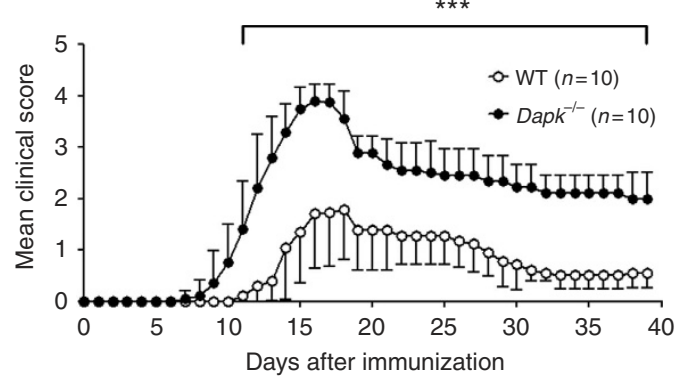

b

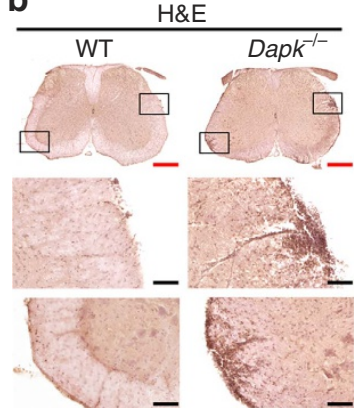

C

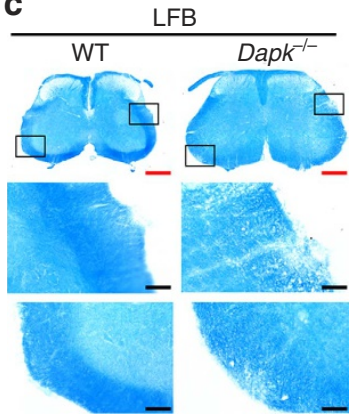

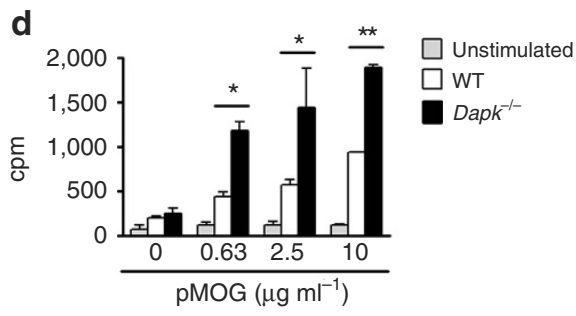

$\mathbf{f}$

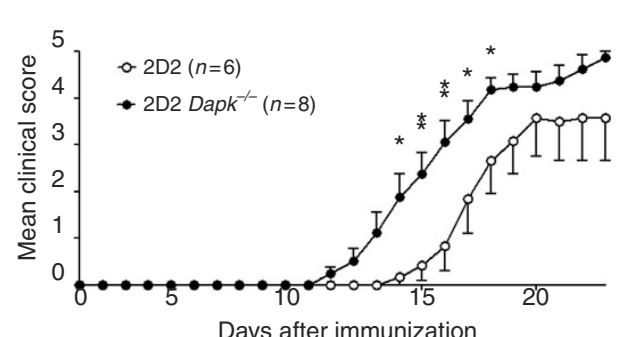

e
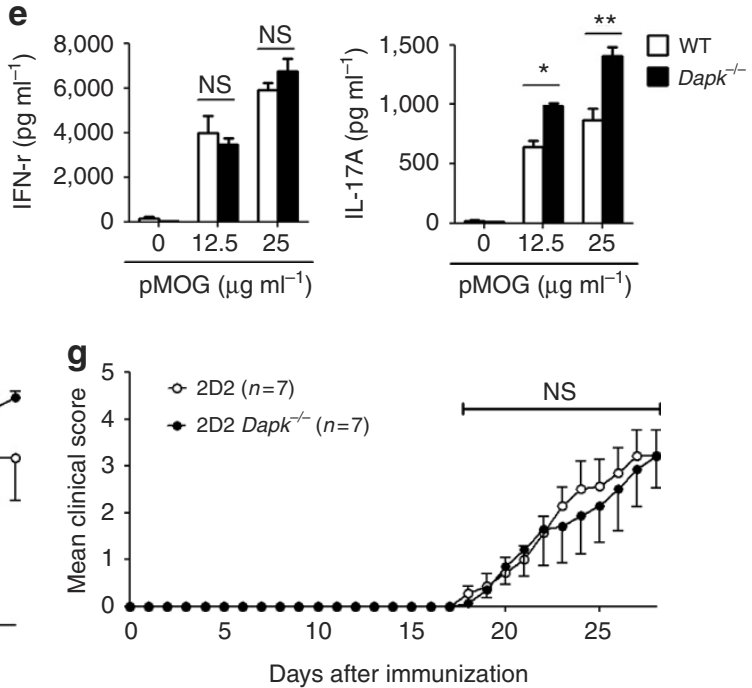

Figure 1 | DAPK deficiency increases T-cell activation and EAE exacerbation. (a) EAE induction in wild-type (WT) and Dapk ${ }^{-/-}$mice. DAPK knockout and WT control mice were immunized with $200 \mu \mathrm{g}$ of myelin oligodendrocyte glycoprotein (MOG) peptide 35-55 emulsified in CFA, followed by intraperitoneal injection of $200 \mathrm{ng}$ pertussis toxin at day 0 and day 2. The progression of disease was monitored. Values are mean $\pm \mathrm{s}$.d. $n=10$ for each group. (b,c) Increased mononuclear cell infiltration and demyelination in spinal cords from primed Dapk ${ }^{-/-}$mice. Spinal cords from WT and Dapk ${ }^{-/-}$ mice were isolated 11 days after MOG immunization, and fixed and frozen sections were obtained. Tissue sections were stained with hematoxylin and eosin (H\&E) (b) and luxol fast blue (LFB) (c). Red scale bar, $400 \mu \mathrm{m}$; black scale bar, $80 \mu \mathrm{m}$. Photos are representative of three mice in each group. (d) Enhanced T-cell response to MOG (33-55) in Dapk ${ }^{-/-}$mice. Splenic CD4 T cells were harvested 9 days after immunization. Cells were stimulated with irradiated autologous presenting cells plus MOG peptide, and the incorporation of thymidine was determined $72 \mathrm{~h}$ later. (e) Increased IL-17 production due to MOG (33-55) stimulation in Dapk ${ }^{-/}-$T cells. The secretion of IFN- $\gamma$ and IL-17 was quantitated in T cells from d. Data (d,e) are mean \pm s.d. $(n=3)$, and are representative of three independent experiments. (f) $2 \mathrm{D} 2 \mathrm{Dapk}^{-/-}$Th17 cells induced exacerbated EAE in Rag ${ }^{-/-}$mice. CD4 ${ }^{+}$T cells from 2D2 or 2D2 Dapk $^{-/-}$mice were differentiated into Th17 cells in vitro. 2D2 or 2D2 Dapk ${ }^{-/-}$Th17 cells were re-stimulated and transferred intravenously to Rag1 ${ }^{-/-}$ mice, followed by intraperitoneal administration of pertussis toxin. Mice were monitored for clinical signs of paralysis and recorded daily. (g) Comparable EAE generation by 2D2 WT Th1 cells and 2D2 Dapk ${ }^{-/-}$Th1 cells in Rag1 ${ }^{-/-}$mice. 2D2 or 2D2 Dapk ${ }^{-/-}$Th1 cells were transferred to Rag ${ }^{-/-}$mice, and clinical signs were monitored, as described in f. Values are mean \pm s.e.m. (f,g). ${ }^{\star} P<0.05,{ }^{\star \star} P<0.01,{ }^{\star \star \star} P<0.001$ for unpaired $t$-test. NS, not significant.

suggesting that DAPK in $\mathrm{T}$ cells negatively regulates EAE pathogenesis.

Both Th17 and Th1 contribute to the development of EAE and multiple sclerosis ${ }^{6}$. Notably, IL-17 production, but not IFN- $\gamma$ generation, was increased in MOG-primed Dapk ${ }^{-1}-\mathrm{T}$ cells (Fig. 1e), suggesting a preferential expansion of DAPK-deficient Th17 cells. We examined the expression of IFN- $\gamma$ and IL-17 in mononuclear cells infiltrated into the spinal cords of EAEinduced mice. During the peak of EAE induction, IFN- $\gamma^{+}$cells were more abundant than IL-17 ${ }^{+}$cells in spinal cords from WT mice (Supplementary Fig. 4a). Conversely, more $\mathrm{IL}-17^{+}$cells than IFN $-\gamma^{+}$cells were detected in the spinal cords from Dapk $k^{-1}$ mice with encephalomyelitis (Supplementary Fig. 4a). Quantitation shows an increased $\mathrm{IL}-17^{+}: \mathrm{IFN}-\gamma^{+}$cells ratio in EAE-inducing Dapk $k^{-1-}$ mice (Supplementary Fig. 4b).

We further examined the induction of EAE in Rag1 ${ }^{-/-}$mice through adoptive transfer of 2D2 T cells. The adoptive transfer of
MOG-specific 2D2 cells that were differentiated into Th17 cells allows for assessment of the effect of DAPK on the induction of antigen-specific and Th17-specific EAE. Dapk-/- 2D2 Th17 cells triggered earlier disease onset and induced more severe encephalomyelitis than WT 2D2 Th17 cells (Fig. 1f). In contrast, the EAE onset and disease severity induced by Dapk-1-2D2 Th1 cells and WT 2D2 Th1 cells were similar (Fig. 1g). Together, these results suggest that DAPK deficiency leads to an increase in encephalitogenic Th17 cells, but not encephalitogenic Th1 cells.

Preferential Th17 differentiation from Dapk ${ }^{-/-}$T cells. We found that expression of DAPK was higher in Th17 cells than Th1 cells (Fig. 2a), consistent with the report that DAPK is induced by TGF- $\beta^{43}$. Therefore, we examined differentiation of Th1 and Th17 cells from Dapk ${ }^{-1}-\mathrm{T}$ cells. Naive CD4 ${ }^{+} \mathrm{T}$ cells from control and Dapk $k^{-1-} \mathrm{T}$ cells were stimulated by 


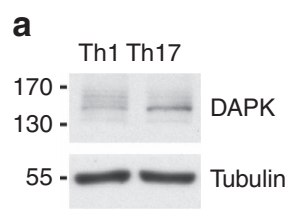

b
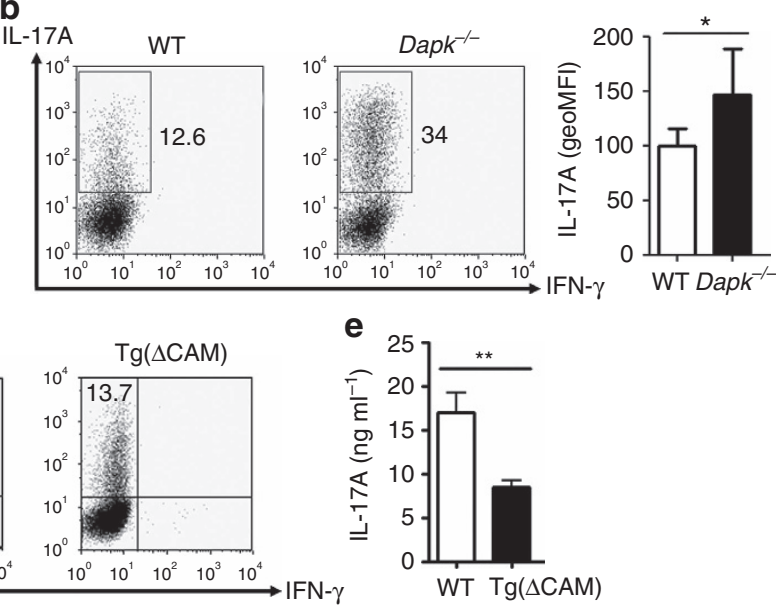

f
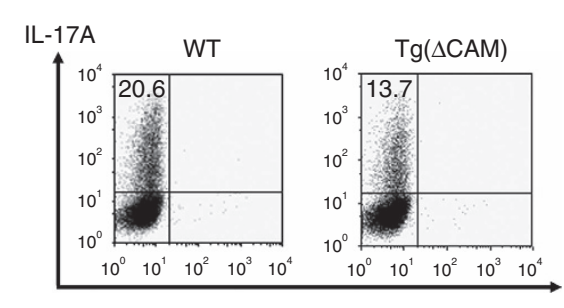$$
\gamma(\triangle C A M)
$$
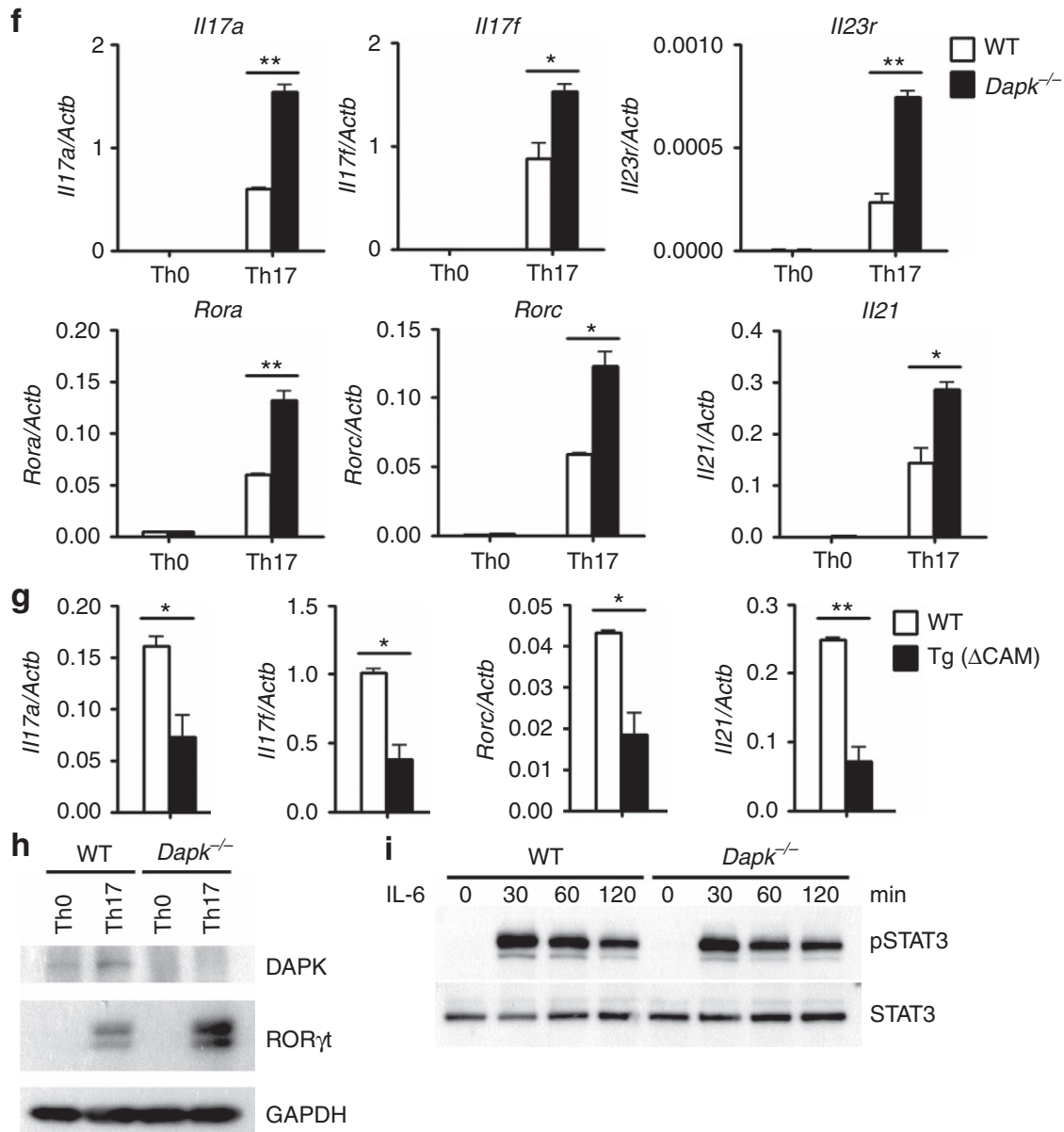

DAPK
ROR $\gamma t$
GAPDH

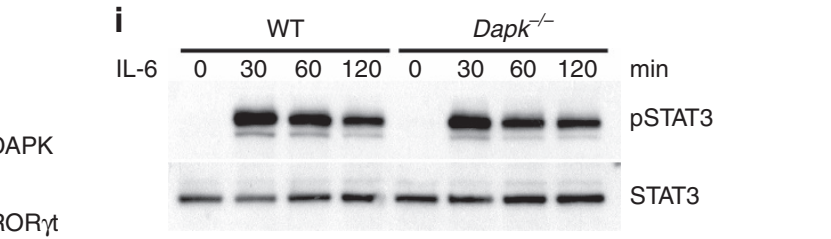

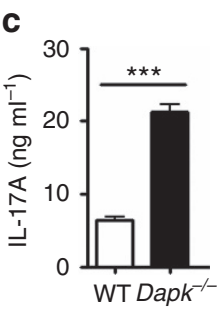

Figure 2 | Enhanced Th17 development in Dapk ${ }^{-/-}$T cells. (a) Increased DAPK levels in Th17 cells. WT naive CD4 (CD4 ${ }^{+} \mathrm{CD}^{-} 5^{-} \mathrm{CD}_{4} 4^{-} \mathrm{CD} 6 \mathrm{~L}^{+}$) T cells were subjected to differentiation into Th1 and Th17 cells for 3 days. The levels of DAPK were determined. (b) Increased IL-17 production in Dapk ${ }^{-/-}$ Th17 cells. WT and Dapk ${ }^{-/-}$Th17 cells differentiated for 5 days were re-stimulated with TPA/A23187 for $4 \mathrm{~h}$ in the presence of monensin during the last $5 \mathrm{~h}$, and the expression of IL-17 and IFN- $\gamma$ were analysed by intracellular staining. The numbers represent the percentages of cells positive (left). The geoMFI is calculated (mean \pm s.d., $n=7$ ) (right). (c) Enhanced IL-17 secretion by Dapk ${ }^{-/}-$Th17 cells. WT and Dapk $-/-$Th17 cells were re-stimulated with TPA/A23187 for $24 \mathrm{~h}$, and the levels of IL-17 in the supernatant were measured by ELISA (mean \pm s.d., $n=3$ ). (d,e) The [ $\Delta$ CAM]DAPK transgene inhibited Th17 differentiation. WT and [ $\triangle$ CAM]DAPK-transgenic T cells were differentiated into Th17 cells for 3 days. The expression of IL-17 and IFN- $\gamma$ were determined after restimulation by intracellular staining (d) or by ELISA (mean \pm s.d., $n=3$ ) (e). (f) Elevated expression of Th17-related genes in Dapk $^{-/-}$T cells. WT and Dapk ${ }^{-/-}$Th0 and Th17 cells were re-stimulated with TPA/A23187 for $3 \mathrm{~h}$, and RNA was isolated. The expression of II17a, II77f, II21, II23r, Rorc and Rora were determined by quantitative PCR (mean \pm s.d., $n=2$ ). (g) Attenuated expression of Th17-associated genes in [ $\Delta$ CAM]DAPKtransgenic T cells. The expression of $1117 a, \| 17 f$, Rorc and $I / 21$ in WT and [ $\Delta$ CAM]DAPK-transgenic Th17 cells were determined as in $\mathbf{f}$. Mean \pm s.d., $n=3$. (h) Increased expression of ROR $\gamma$ t protein in Dapk ${ }^{-/-}$Th17 cells. A fraction of the TPA/A23187-re-stimulated cells from $\mathbf{b}$ were analysed for ROR $\gamma \mathrm{t}$ expression by western blot. (i) Normal STAT3 activation in Dapk ${ }^{-/-}$T cells. Freshly isolated WT and Dapk ${ }^{-/-}$T cells were stimulated with IL-6 for the indicated times. The levels of phospho-STAT3 and total STAT3 were examined by western blotting. Data $(\mathbf{a}, \mathbf{c}-\mathbf{i})$ are representative of three independent experiments. ${ }^{\star} P<0.05,{ }^{\star \star} P<0.01,{ }^{\star \star \star} P<0.001$ for unpaired $t$-test. 
CD3/CD28 in the presence of TGF- $\beta$ and IL-6 to induce Th17 differentiation. Differentiation into Th17 was significantly increased for Dapk-1- T cells, with the IL-17-producing population significantly larger in Dapk ${ }^{-/-}$Th17 cells relative to the WT (Fig. 2b, left panel), as also illustrated by an elevated mean fluorescence intensity (MFI; Fig. 2b, right panel). This was also confirmed by ELISA, which showed a threefold increase in IL-17 secretion by Dapk ${ }^{-1-}$ Th17 cells compared with control Th17 cells (Fig. 2 c). In addition, for Th17 cells induced by IL-21 and TGF- $\beta$, IL-17 production also increased approximately threefold for Dapk ${ }^{-/}$Th17 cells (Supplementary Fig. 5a). A similar extent of increase in IL-17 expression was found for Dapk ${ }^{-I}$ Th17 cells induced by TGF- $\beta$, IL-1 $\beta$, IL-6 and IL-23 (Supplementary Fig. 5b). However, no effect was found on DAPK deficiency in Th17 cells induced by IL-1 $\beta$, IL- 6 and IL-23 (ref. 45; Supplementary Fig. 5c), suggesting that regulation of Th17 by DAPK depends on priming with TGF- $\beta$. In parallel experiments, T-cell-specific transgenic expression of [ $\triangle \mathrm{CAM}] \mathrm{DAPK}$ attenuated Th17 differentiation mediated by TGF- $\beta$ and IL-6
(Fig. 2d,e). Together, these results suggest that DAPK inhibits TGF- $\beta$-dependent Th17 development.

Elevated ROR $\gamma$ t and ROR $\alpha$ in Dapk ${ }^{-/-}$Th17 cells. We then determined whether the increased production of IL-17 correlated with enhanced induction of the transcription of $I l 17$ genes. Quantitative PCR confirmed that the expression of Ill7a and Il17f was elevated in DAPK-deficient Th17 cells relative to the WT Th17 cells (Fig. 2f), implying that enhanced IL-17 generation could be partly attributed to increased expression of their mRNAs. Induction of $I l 21$ and $I l 23 r$ - the cytokine and receptor preferentially expressed in Th17 cells, respectively-were also increased in Dapk $k^{-1-}$ Th17 cells. In addition, levels of Rorc and Rora-the master transcription factors determining the expression of IL-17-were twofold higher in DAPK-null Th17 cells compared with control Th17 cells (Fig. 2f), which correlated with the elevated protein levels of ROR $\gamma \mathrm{t}$ in Dapk-I- Th17 cells (Fig. 2h). As a control, in the activated Th0 cells, Il17a, Il17f, Il21, a

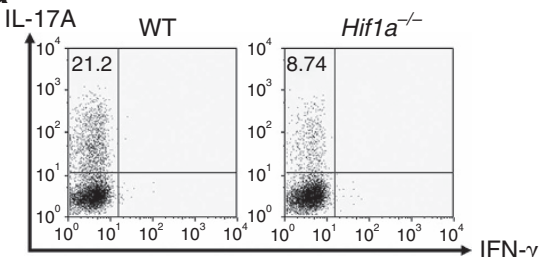

b

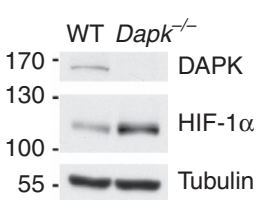

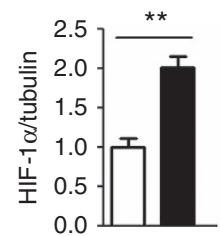

C

e
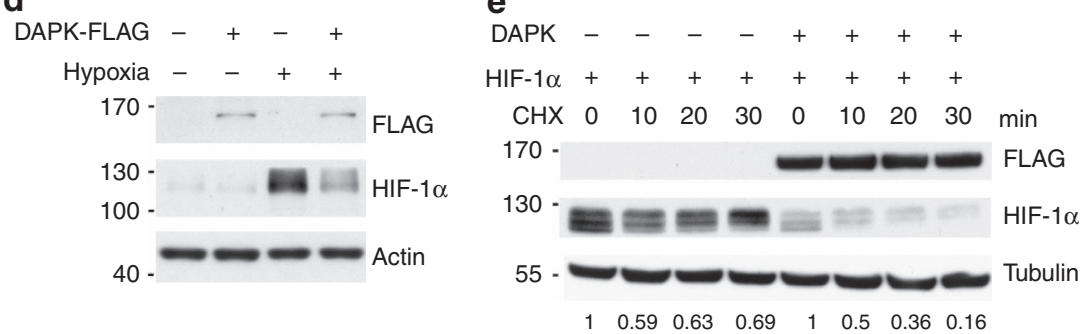

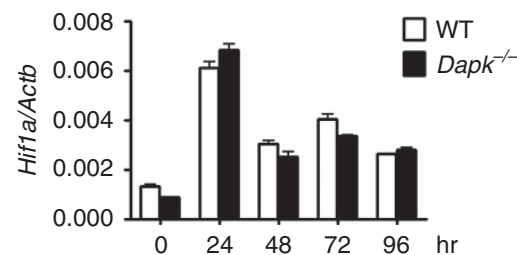

f
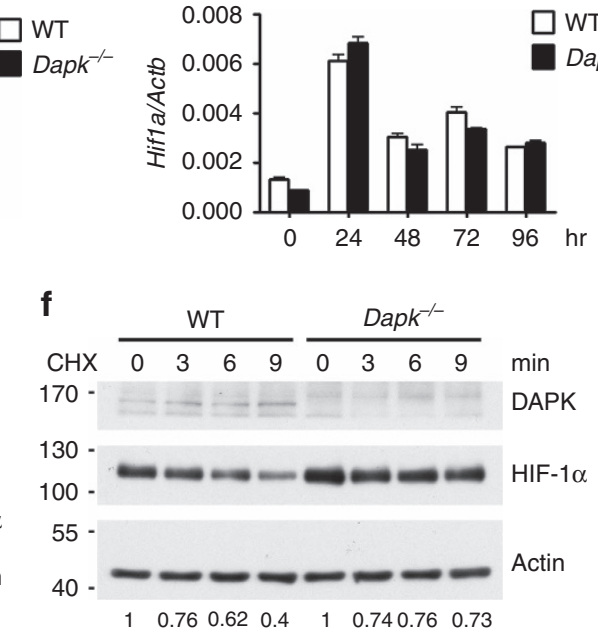

g

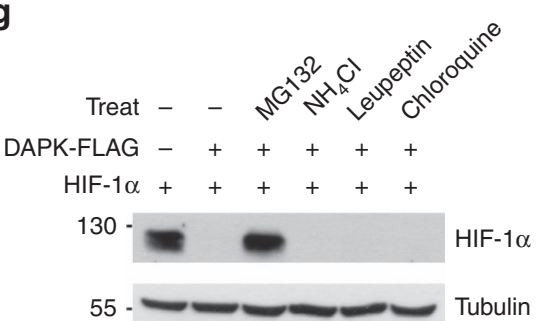

h WT KO WT KO MG132 - - + +

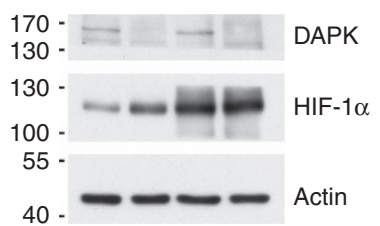

i

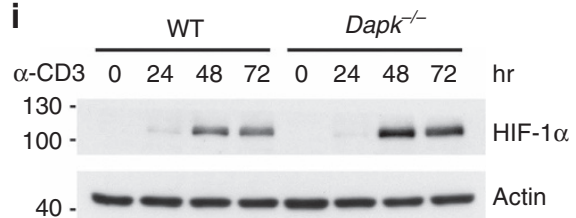

Figure 3 | DAPK promotes HIF-1 $\alpha$ degradation and DAPK deficiency increases HIF-1 $\alpha$ levels in T cells. (a) HIF- $1 \alpha$ deficiency impairs Th17 differentiation. WT and Hifla ${ }^{-/}-$Th17 cells were re-stimulated and expression of IL-17A and IFN- $\gamma$ determined. (b) Enhanced HIF- $1 \alpha$ protein levels in Dapk ${ }^{-/-}$Th17 cells. HIF-1 $\alpha$ protein contents were determined in Th17 cells differentiated for 3 days (left). HIF-1 $\alpha$ levels were quantified and normalized to tubulin (right). Mean \pm s.e.m., $n=3$. ${ }^{\star \star} P<0.01$ for unpaired $t$-test. (c) DAPK-knockout does not affect HIF-1 $\alpha$ mRNA induction during Th17 differentiation. The quantities of Hifla transcript were determined in WT and Dapk ${ }^{-/-}$T cells in the course of Th17 differentiation. Mean \pm s.e.m., $n=3$. (d) DAPK induces HIF- $1 \alpha$ protein downregulation in normal T cells. Activated primary T cells were transduced with DAPK-FLAG. GFP + T cells were sorted, incubated under hypoxic conditions for $48 \mathrm{~h}$, and the levels of DAPK-FLAG and HIF-l $\alpha$ were determined. (e) DAPK reduces HIF- $1 \alpha$ protein stability. HEK293T cells were transfected with DAPK and HIF- $1 \alpha$, treated with $\mathrm{CHX}\left(50 \mathrm{ng} \mathrm{ml}^{-1}\right) 48 \mathrm{~h}$ later, and the levels of HIF-1 $\alpha$ and DAPK were measured. HIF- $1 \alpha$ levels were quantified. (f) DAPK deficiency increases HIF-1 $\alpha$ protein stability in T cells. WT and Dapk ${ }^{-/-}$CD4 ${ }^{+}$T cells were differentiated into Th17 cells for 2 days, followed by $\mathrm{CHX}\left(25 \mathrm{ng} \mathrm{ml}^{-1}\right)$ treatment. The levels of HIF-1 $\alpha$ protein were determined by immunoblots and were quantified. (g) DAPK-induced HIF- $1 \alpha$ degradation is inhibited by MG132. HEK293T cells were transfected with DAPK and HIF-l $\alpha$. Forty-eight hours later, cells were treated with $10 \mu \mathrm{M} \mathrm{MG132,200} \mathrm{mM} \mathrm{NH}{ }_{4} \mathrm{Cl}$, $100 \mu \mathrm{g} \mathrm{ml}^{-1}$ leupeptin, or $100 \mu \mathrm{M}$ chloroquine for $6 \mathrm{~h}$. The HIF-1 $\alpha$ levels were determined. (h) DAPK-induced HIF-1 $\alpha$ degradation is proteasome-dependent. WT and Dapk $-/-$ CD4 ${ }^{+}$T cells were differentiated into Th17 cells for 2 days, followed by MG132 (5 $\mu$ M) treatment for $2 \mathrm{~h}$. The levels of HIF- $1 \alpha$ were determined. (i) DAPK deficiency increases the induction of HIF-1 $\alpha$ protein in T cells. WT and Dapk-/- T cells were activated with CD3/CD28 under normoxic conditions, and the levels of HIF- $1 \alpha$ at the indicated time points were determined. Data are representative of three (a,c,e-i) or two (d) independent experiments. 
Il23r, Rorc and Rora were absent (Fig. 2f). In addition, the expression of Il17a, Illff, Rorc and Il21 was inhibited in [ $\triangle$ CAM]DAPK-transgenic Th17 cells (Fig. 2g). Together, these results suggest that DAPK suppresses Th17 differentiation by inhibiting the induction of ROR $\gamma t$ and $\operatorname{ROR} \alpha$.

In parallel experiments, $T$ cells were primed with IL-12 for Th1 differentiation. Supplementary Fig. $5 \mathrm{~d}$ illustrates that the development into Th1 cells was comparable between WT and Dapk ${ }^{-I}-\mathrm{T}$ cells. Consistent with this result, the expression of Tbx21 (T-bet) and Ifng was not affected by the deficiency of DAPK (Supplementary Fig. 5e). Similarly, differentiation into Th1 cells was not altered by the $[\triangle \mathrm{CAM}] \mathrm{DAPK}$ transgene (Supplementary Fig. 5f).

Since DAPK targets Rorc expression, we further examined whether the transcription factors regulating ROR $\gamma \mathrm{t}$ expression were modulated by DAPK. STAT3 is known to activate the Rorc promoter and promote Th17 cell development ${ }^{12-16,46}$. Figure $2 \mathrm{i}$ demonstrates that the levels of STAT3 were comparable between WT and Dapk-1- T cells. IL-6-triggered STAT3 phosphorylation was also similar between control and Dapk $k^{-/-}$ T cells (Fig. 2i). Similarly, IL-21-triggered STAT3 phosphorylation was comparable between WT and Dapk-1- $\mathrm{T}$ cells (Supplementary Fig. 5g). Therefore, DAPK deficiency does not appear to interfere with STAT3 expression and activation.

We also determined whether activation of the IL-17 promoter by $\mathrm{ROR} \gamma \mathrm{t}$ and $\mathrm{ROR} \alpha$ was regulated by DAPK. To exclude interference from endogenous DAPK, DAPK was knocked down in $293 \mathrm{~T}$ cells by siRNA targets to its $5^{\prime}$ UTR (Supplementary Fig. 6a). IL-17P-Luc was activated in $293 \mathrm{~T}$ cells by co-transfection with ROR $\gamma$ t (Supplementary Fig. 6b). Co-expression of ROR $\gamma \mathrm{t}$ with DAPK, the dominant negative DAPK [K42A]DAPK or [ $\triangle \mathrm{CAM}] \mathrm{DAPK}$ all inhibited ROR $\gamma$ t-directed $I l 17$ promoter activation. Similarly, ROR $\alpha$-mediated IL-17P-Luc activation was inhibited by co-expression of ROR $\alpha$ with DAPK, [K42A]DAPK or $[\triangle \mathrm{CAM}] \mathrm{DAPK}$ (Supplementary Fig. 6c). Therefore, DAPK likely inhibits Th17 development at two sequential stages, that is, expression of both $\operatorname{ROR} \gamma \mathrm{t}$ and $\mathrm{ROR} \alpha$ as well as $\mathrm{ROR} \gamma \mathrm{t} / \mathrm{ROR} \alpha-$ mediated IL-17 expression.

DAPK downregulates HIF-1 $\alpha$ in Th17 differentiation. It has been previously shown that HIF- $1 \alpha$ promotes Th17 differentiation ${ }^{26,27}$. Consistent with this observation, diminished Th17 differentiation was found in $\mathrm{Hifla}^{-/-} \mathrm{T}$ cells (Fig. 3a). HIF- $1 \alpha$ is known for its participation in carcinogenesis ${ }^{18,19}$, while DAPK is a tumour suppressor. Therefore, we investigated whether DAPK directly modulated the expression of HIF- $1 \alpha$. HIF-1 $\alpha$ was upregulated in Dapk ${ }^{-/}-$Th17 cells (Fig. 3b), which correlated with the enhanced IL-17 expression in the knockout $\mathrm{T}$ cells. The increased HIF- $1 \alpha$ protein in Dapk ${ }^{-1-} \mathrm{T}$ cells was not due to an increase in Hifla mRNA, as Hifla transcript levels were comparable between WT and Dapk ${ }^{-1-} \mathrm{T}$ cells during the course of Th17 differentiation (Fig. 3c). Because HIF-1 $\alpha$ expression is regulated by the mTORC1 pathway ${ }^{24,47,48}$, we examined whether DAPK deficiency affected mTORC1 signalling in T cells. Expression and phosphorylation of mTOR were similar between WT and Dapk ${ }^{-}-$Th17 cells (Supplementary Fig. 7a). Further, activation of the mTOR substrates p70 S6 kinase and 4EBP1 in Th17 cells was not affected by DAPK deficiency (Supplementary Fig. 7a). Similarly, p70 S6 kinase-mediated phosphorylation of ribosomal S6 at S235 and S240 was comparable between WT and Dapk ${ }^{-1-}$ T cells (Supplementary Fig. $7 \mathrm{~b}, \mathrm{c})$. In addition, overexpression of DAPK downregulated the levels of HIF- $1 \alpha$ in normal T cells cultured under hypoxic conditions (Fig. 3d). Together, these results suggest that DAPK targets HIF- $1 \alpha$ at the post-transcriptional level.
We next examined the effect of DAPK on the stability of HIF- $1 \alpha$. Cycloheximide-induced HIF- $1 \alpha$ protein instability was enhanced by the presence of DAPK in 293 T cells (Fig. 3e), while HIF- $1 \alpha$ protein stability was increased in DAPK-deficient Th17 cells (Fig. 3f), suggesting that DAPK promotes HIF-1 $\alpha$ protein destabilization. DAPK-induced HIF-1 $\alpha$ protein downregulation was inhibited by MG132 in $293 \mathrm{~T}$ cells, but not by $\mathrm{NH}_{4} \mathrm{Cl}$, leupeptin or chloroquine (Fig. 3g). In addition, MG132 treatment increased HIF- $1 \alpha$ to similar levels in WT and Dapk ${ }^{-/-}$Th17 cells (Fig. 3h). These results suggest the involvement of the proteasome degradation pathway in DAPK-mediated HIF- $1 \alpha$ downregulation in Th17 cells.

In a separate experiment, we examined whether HIF- $1 \alpha$ protein expression could be induced by prolonged TCR activation in $\mathrm{T}$ cells under normoxic conditions (Fig. 3i). CD3-induced HIF- $1 \alpha$ protein expression was much higher in Dapk $k^{-1}-$ T cells than WT T cells (Fig. 3i), further illustrating the ability of DAPK to downregulate HIF- $1 \alpha$ protein.

HIF- $1 \alpha$ has also been shown to antagonize Foxp3 and inhibit regulatory $\mathrm{T}$ cells (Treg) ${ }^{27,49}$. The development and in vitro suppressive activity of natural regulatory cells (nTreg) were not affected in Dapk $k^{-1-}$ nTregs (Supplementary Fig. 8a,b). However, the differentiation of induced regulatory $\mathrm{T}$ cells (iTreg) from $\mathrm{CD} 4{ }^{+} \mathrm{CD} 25^{-} \mathrm{T}$ cells was moderately impaired in Dapk $k^{-1}$ T cells (Supplementary Fig. 8c). The in vitro suppressive activity of Dapk-1- iTregs was also reduced relative to WT iTregs (Supplementary Fig. 8d).

DAPK interacts with cytoplasmic HIF-1 $\alpha$ in T cells. To isolate the mechanism underlying DAPK-dependent HIF- $1 \alpha$ degradation, we next examined whether there was a direct interaction between DAPK and HIF-1 $\alpha$. DAPK is a cytosolic protein whereas HIF- $1 \alpha$ is known for its predominant nuclear localization, as shown in hypoxic HeLa cells (Fig. 4a). HIF-1 $\alpha$ was induced in $\mathrm{T}$ cells through prolonged TCR stimulation (Fig. 3i), followed by immunoblotting to determine its localization. Some HIF-1 $\alpha$ was present in the cytosolic fraction of activated T cells (Fig. 4b). Similarly, the presence of HIF-1 $\alpha$ was detected in the cytoplasmic fraction of Th17 cells (Fig. 4c). The cytosolic localization of HIF- $1 \alpha$ in Th17 cells, but not in HeLa cells, was further confirmed by confocal microscopy (Fig. 4 d). In addition, DAPK co-localized with HIF- $1 \alpha$ in the cytoplasm of hypoxic Jurkat cells (Fig. 4e), as well as in the cytosol of normoxic Th17 and Th0 cells (Fig. 4f).

Since HIF- $1 \alpha$ and DAPK co-localized to the cytoplasm, we looked for (and found, see Fig. 4g) their direct interaction by co-immunoprecipitation. The cytoskeleton-binding domain of DAPK was required for the association with HIF-1 $\alpha$ (Fig. 4h), while the N-terminal domain of HIF- $1 \alpha$ interacted with DAPK (Supplementary Fig. 9a). The association of DAPK with endogenous HIF-1 $\alpha$ was also observed in hypoxic $\mathrm{T}$ cells (Fig. 4i). Together, these results suggest that DAPK interacts with HIF- $1 \alpha$ in the cytosol of T cells, and DAPK may regulate the protein stability of HIF-1 $\alpha$ through this direct binding. We also examined whether the kinase domain of DAPK participates in the downregulation of HIF-1 $\alpha$. An N-terminal DAPK fragment containing the kinase domain and ankyrin repeats weakly reduced HIF- $1 \alpha$ expression, while a C-terminal DAPK segment from the cytoskeleton binding to death domain effectively promoted HIF-1 $\alpha$ degradation (Supplementary Fig. 9b). In addition, we found that HIF- $1 \alpha$ is not a kinase substrate of DAPK since recombinant HIF- $1 \alpha$ was not phosphorylated by DAPK in vitro (Supplementary Fig. 9c,d). Therefore, even though DAPK binds HIF- $1 \alpha$ and induces HIF- $1 \alpha$ protein instability, the kinase domain of DAPK appears to be disposable in HIF-1 $\alpha$ downregulation. 

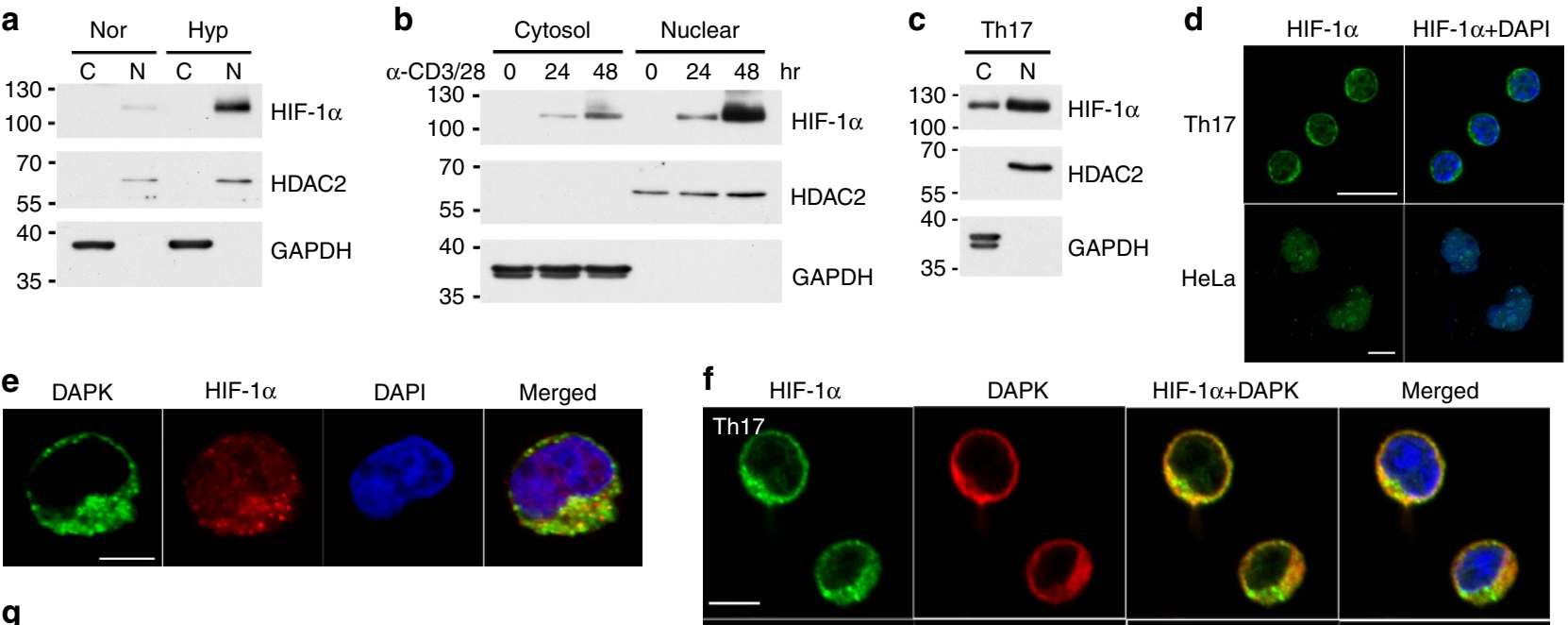

HIF-1 $\alpha+$ DAPK
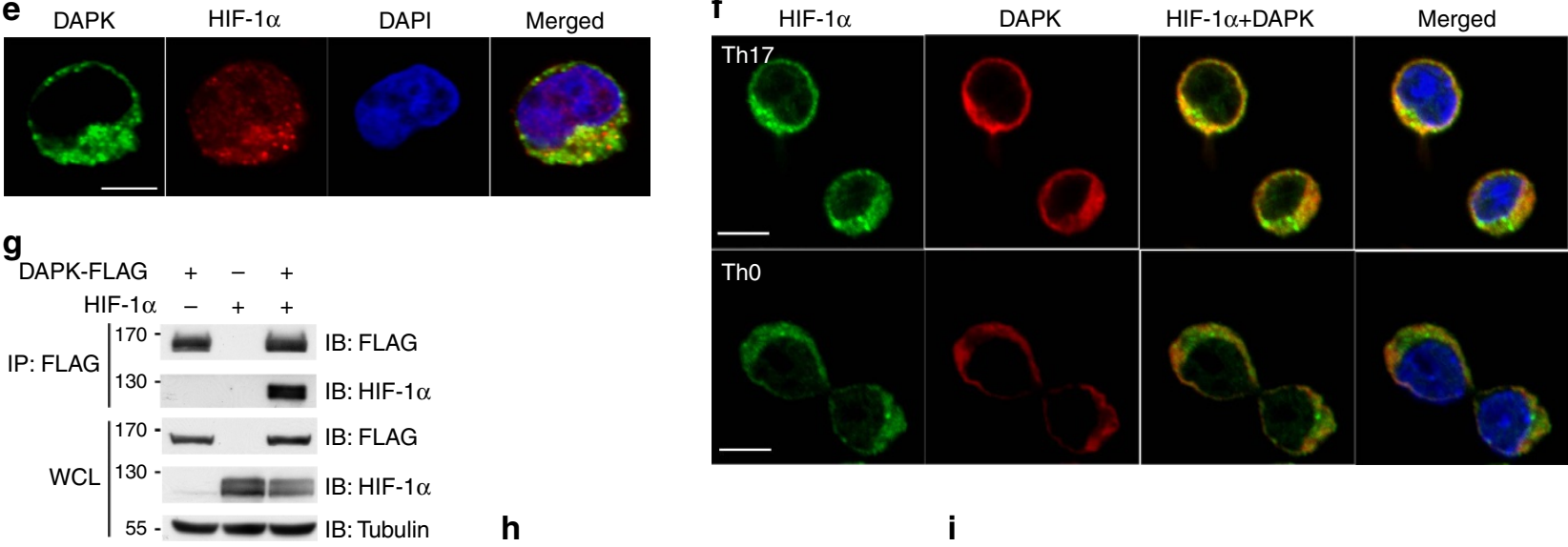

h DAPK-FLAG - WT $\triangle$ Cyto
HIF-1 $\alpha-H A+++$
$\mid 170-+$

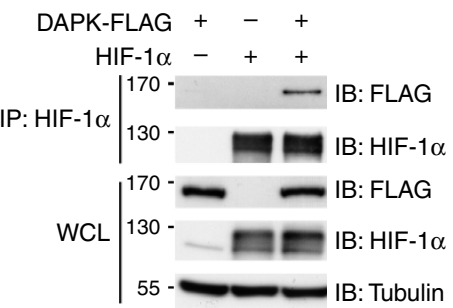

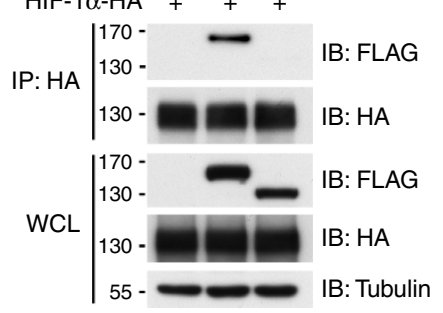

Figure 4 | Cytoplasmic presence of HIF-1 $\alpha$ and co-localization with DAPK in T cells. (a) Predominant nuclear location of HIF-1 $\alpha$ in HeLa cells. HeLa cells were cultured in normoxic or hypoxic $\left(1 \% \mathrm{O}_{2}\right)$ conditions for $24 \mathrm{~h}$. Nuclear ( $\mathrm{N}$ ) and cytoplasmic (C) fractions were isolated, and HIF-1 $\alpha$ expression levels were determined. HDAC2 and GAPDH were used as the nuclear marker and cytosolic marker, respectively. (b,c) Cytoplasmic presence of HIF-1 $\alpha$ in T cells. WT T cells were activated with anti-CD3/CD28 for the indicated times (b), while naive CD4 ${ }^{+}$T cells were differentiated into Th17 for 48 h (c). Nuclear and cytoplasmic fractions were prepared, and HIF-1 $\alpha$ expressions were examined. (d) Image analysis of HIF-1 $\alpha$ localization in Th17 and HeLa cells. Th17 cells (c) and HeLa cells (a) were stained with anti-HIF-1 $\alpha$ and DAPI and analysed by confocal microscopy. Scale bar, $10 \mu$ m. (e) Co-localization of HIF-1 $\alpha$ and DAPK in Jurkat cells. DAPK-FLAG-overexpressing Jurkat cells were cultured under hypoxic $\left(1 \% \mathrm{O}_{2}\right)$ conditions for $4 \mathrm{~h}$, fixed and stained with anti-FLAG, anti-HIF- $1 \alpha$ and DAPI, and analysed by confocal microscopy. Scale bar, $5 \mu \mathrm{m}$. (f) Co-localization of HIF- $1 \alpha$ and DAPK in Th17 and Th0 cells. WT naive T cells were differentiated into Th17 (top) or Th0 cells (bottom) for 2 days, fixed and stained with anti-HIF-1 $\alpha$, anti-DAPK and DAPI, and analysed by confocal microscopy. Scale bar, $5 \mu \mathrm{m}$. (g) Interaction between HIF-1 $\alpha$ and DAPK. HEK293T cells were transfected with DAPK-FLAG or HIF-1 $\alpha$, as indicated. The whole-cell lysates (WCL) were immunoprecipitated with either anti-FLAG (top) or anti-HIF-1 $\alpha$ (bottom). The contents of DAPK-FLAG and HIF-1 $\alpha$ in the precipitates and lysates were determined. (h) Involvement of the DAPK cytoskeleton domain in HIF-1 $\alpha$ binding. HEK293T cells were transfected with HIF- $1 \alpha-H A$, and WT DAPK-FLAG or DAPK( $\Delta$ Cyto)-FLAG. The WCL were immunoprecipitated with anti-HA, and the amounts of DAPK and HIF-1 $\alpha$ were determined. (i) Association of DAPK with the endogenous HIF- $1 \alpha$ in hypoxic T cells. DAPK in normoxic and hypoxic (1\% $\mathrm{O}_{2}$ for $4 \mathrm{~h}$ ) Jurkat cells was precipitated by anti-DAPK, and amounts of the associated HIF-1 $\alpha$ were determined by western blot. Data are representative of three (a-h) or two (i) independent experiments.

DAPK induces PHD2-mediated HIF-1 $\alpha$ degradation. The inclusion of ubiquitin enhanced the ability of DAPK to downregulate HIF-1 $\alpha$ (Supplementary Fig. 10a), illustrating the involvement of the ubiquitin-dependent degradation process. The stability of HIF- $1 \alpha$ protein is regulated by proline hydroxylation, a step necessary for its subsequent binding to VHL protein leading to ubiquitination and proteasome degradation ${ }^{18-20,22}$. Therefore, we sought to identify the degradation pathways responsible for DAPK-regulated HIF- $1 \alpha$ stability. Deletion of the HIF- $1 \alpha$ oxygen-dependent degradation domain containing the proline residues necessary for hydroxylation conferred resistance to DAPK-induced degradation (Fig. 5a). Similarly, inhibition of $\mathrm{PHD} 1 / 2$, which hydroxylates HIF-1 $\alpha$ protein, by deferoxamine mesylate (DFX) restored the expression levels of HIF- $1 \alpha$ protein in DAPK-expressing T cells and in 293T cells (Fig. 5b; Supplementary Fig. 10b). This result was consistent with the decreased hydroxylation of HIF- $1 \alpha$ protein at proline 564 in Dapk $k^{-/-} \mathrm{T}$ cells (Fig. 5c) and the increased proline 564 hydroxylation in DAPK-overexpressing Jurkat cells (Fig. 5d). Mutation of the hydroxylation sites Pro402 and Pro564 on HIF- $1 \alpha$ into alanine (2PA) conferred resistance of HIF- $1 \alpha$ protein to DAPK-induced degradation in T cells and in HEK293T cells 
a

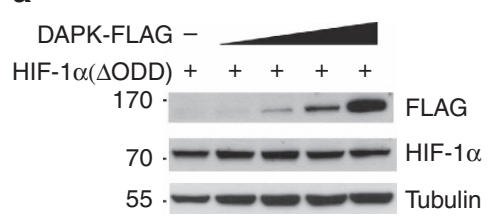

b

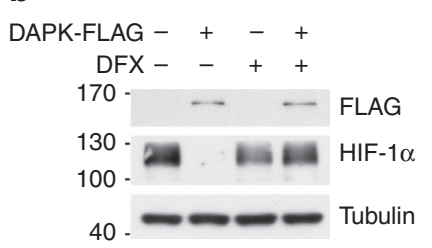

C

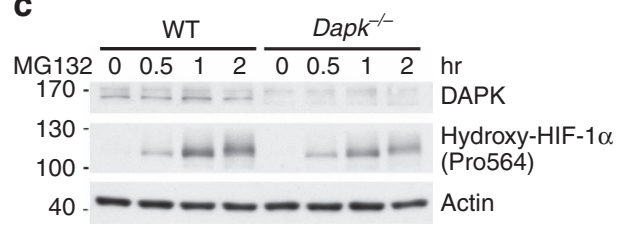

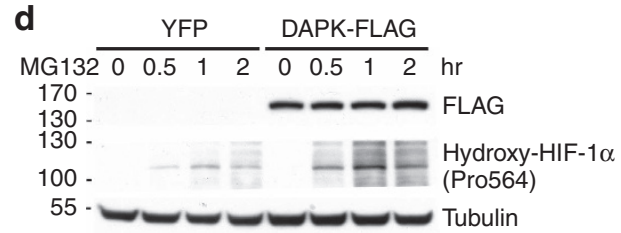

g

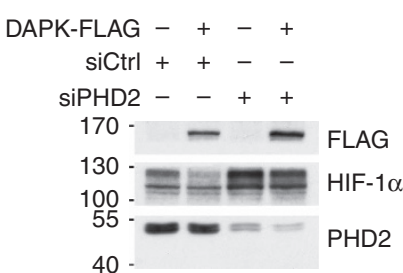

40 e

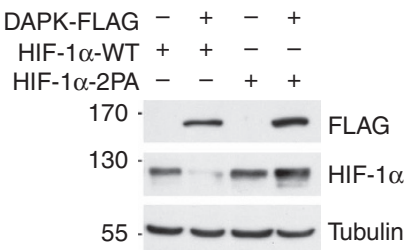

f

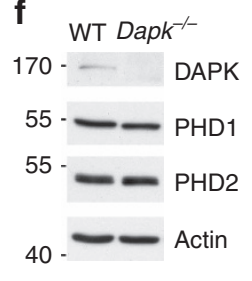

Figure 5 | DAPK promotes PHD2-dependent HIF-1 $\alpha$ degradation. (a) Deletion of the oxygen-dependent degradation (ODD) region confers resistance of HIF-1 $\alpha$ to DAPK-induced degradation. HEK293T cells were transfected with DAPK-FLAG and HIF- $1 \alpha[\Delta O D D]$ and the levels of HIF-1 $\alpha$ were determined $48 \mathrm{~h}$ after transfection. (b) PHD inhibitor prevents DAPK-induced HIF-1 $\alpha$ degradation in normal T cells. Naive T cells were activated for $48 \mathrm{~h}$ and transduced with vector or DAPK-FLAG-IRES-GFP. GFP + T cells were sorted $48 \mathrm{~h}$ later, switched to hypoxic incubation $\left(1 \% \mathrm{O}_{2}\right)$ in the absence or presence of DFX (10 $\left.\mu \mathrm{M}\right)$ for another $24 \mathrm{~h}$, and the levels of DAPK-FLAG and HIF-1 $\alpha$ were determined. (c) DAPK deficiency decreases proline hydroxylation of HIF- $1 \alpha$ in normal T cells. Naive WT and Dapk ${ }^{-/}-$T cells were activated with anti-CD3/CD28 for $48 \mathrm{~h}$ in normoxic conditions, followed by treatment with MG132 (10 $\mu$ M). The extents of Pro564 hydroxylation on HIF- $1 \alpha$ were determined at the indicated time points. (d) DAPK enhances proline hydroxylation of HIF- $1 \alpha$. YFP control and DAPK-FLAG-expressing Jurkat cells were treated with MG132 $(5 \mu \mathrm{M})$ in normoxic conditions. The extents of Pro564 hydroxylation on HIF-1 $\alpha$ were determined at the indicated time points. (e) Mutation of proline hydroxylation sites confers resistance of HIF- $1 \alpha$ to DAPK-induced degradation in T cells. Jurkat cells were transfected with DAPK-FLAG, HIF-1 $\alpha$-WT or HIF-1 $\alpha[$ P402A/P564A] (HIF-1 $\alpha-2$ PA), as indicated. Twenty-four hours after transfection, cells were incubated under hypoxic conditions $\left(1 \% \mathrm{O}_{2}\right)$ for $6 \mathrm{~h}$, then switched back to normoxia for 10 min, and the levels of HIF- $1 \alpha$ were determined. (f) DAPK deficiency does not affect the expression of PHD1 and PHD2. WT and Dapk ${ }^{-/-}$naive CD4 T cells were allowed to differentiate into Th17 cells for 3 days. Cells were harvested and the expression of PHD1 and PHD2 was examined. (g) PHD2-knockdown prevents DAPK-induced HIF-1 $\alpha$ degradation in T cells. Jurkat T cells were transfected with DAPK-FLAG, siRNA control (siCtrl), or siRNA for PHD2 (siPHD2). Twenty-four hours later, cells were switched to hypoxic conditions for $6 \mathrm{~h}$, and the levels of HIF- $1 \alpha$, PHD2 and HSP90 were determined. Data are representative of three (a,d) or two $(\mathbf{b}, \mathbf{c}, \mathbf{e}-\mathbf{g})$ independent experiments.

(Fig. 5e; Supplementary Fig. 10c). We confirmed that DAPK deficiency did not affect the levels of PHD1 and PHD2 in T cells (Fig. 5f). However, knockdown of PHD2 prevented DAPKinduced HIF- $1 \alpha$ degradation in T cells (Fig. 5g). Taken together, these results suggest that DAPK-induced HIF- $1 \alpha$ downregulation is partly mediated by PHD2-triggered proline hydroxylation on HIF- $1 \alpha$.

We further detected an interaction between DAPK and PHD2 in T cells (Fig. 6a). Co-localization of DAPK with PHD2 was observed in Th17 cells by confocal microscopy (Fig. 6b). In addition, PHD2 co-localized with HIF- $1 \alpha$ in the nucleus and cytoplasm of Th17 cells (Fig. 6c). We also identified the $\mathrm{N}$-terminal part (aa 1-180) of PHD2 as the DAPK-interacting region (Fig. 6d). Addition of recombinant DAPK protein enhanced the interaction of GST-HIF- $1 \alpha$ and FLAG-PHD2 in an in vitro binding assay (Fig. 6e). Therefore, by binding to both HIF- $1 \alpha$ and PHD2, a possible role for DAPK is to enhance the association of PHD2 with HIF- $1 \alpha$ and increase HIF- $1 \alpha$ degradation.

HIF-1 $\alpha$ knockout inhibits Dapk ${ }^{-/-}$Th17 cell differentiation. We hypothesized that if the excess generation of IL-17 in Dapk ${ }^{-/-}$
T cells is due to enhanced HIF- $1 \alpha$-mediated Th17 differentiation, the additional deletion of HIF- $1 \alpha$ should reduce IL-17 production to normal levels in Dapk ${ }^{-/}-\mathrm{T}$ cells. We generated mice with Dapk $k^{-/-} H i f 1 a^{-/-}$by crossing mice with T-cell-specific

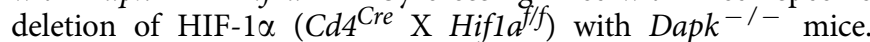
Deletion of HIF- $1 \alpha$ and/or DAPK in T cells from each genotype was confirmed by immunoblotting (Fig. 7a). In agreement with our hypothesis, we found that while Dapk $-1-\mathrm{T}$ cells exhibited enhanced differentiation of naive $\mathrm{CD} 4^{+} \mathrm{T}$ cells into Th17 cells, Dapk $k^{-/} H_{i f 1 a^{-/-}} \mathrm{T}$ cells displayed levels similar to WT T cells (Fig. 7b). Knockout of HIF- $1 \alpha$ also decreased the levels of ROR $\gamma \mathrm{t}$ in Dapk ${ }^{-/-}$Th17 cells (Fig. 7c). Therefore, elevated HIF- $1 \alpha$ levels partly account for the increased IL-17 expression in Dapk $k^{-1-} \mathrm{T}$ cells. We further examined whether selective deletion of HIF- $1 \alpha$ in T cells attenuated the exacerbated EAE generation in Dapk $k^{-1-}$ mice. The severe EAE disease scores in Dapk $k^{-1}$ mice were largely attenuated by T-cell-selective deletion of HIF-1 $\alpha$ (Fig. 7d), supporting that DAPK acts upstream of HIF-1 $\alpha$ in EAE development. T-cell-specific deletion of HIF- $1 \alpha$ did not affect the development and suppressive activity of nTreg in Dapk $k^{-1-}$ mice (Supplementary Fig. 11a,b). The reduced development of Dapk ${ }^{-}-$iTregs was restored by HIF-1 $\alpha$ knockout (Supplementary Fig. 11c), yet the impaired 
a
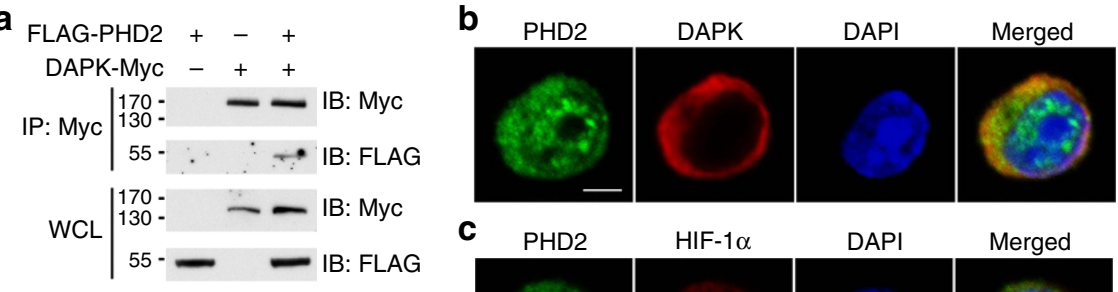

d

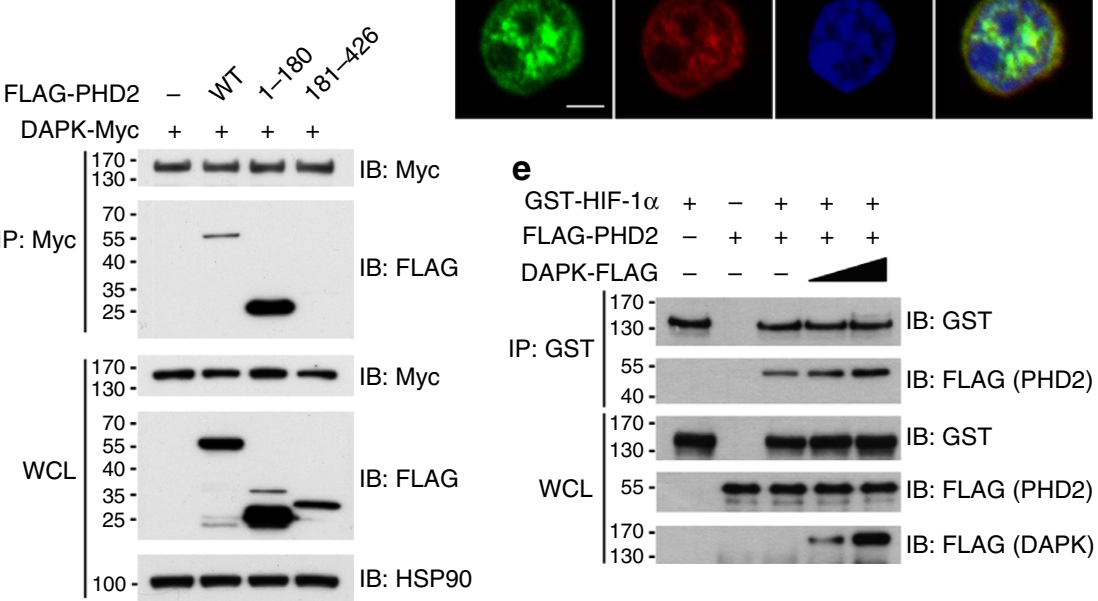

Figure 6 | DAPK interacts with PHD2 and increases PHD2-HIF-1 $\alpha$ association. (a) Interaction of DAPK with PHD2. Jurkat cells were transfected with FLAG-PHD2 and DAPK-Myc. The whole-cell lysates (WCL) were immunoprecipitated with anti-Myc, and the contents of FLAG-PHD2 and DAPK-Myc in the precipitates and WCL were determined by anti-FLAG and anti-Myc. (b) Co-localization of DAPK with PHD2 in Th17 cells. WT naive T cells were differentiated into Th17 for 2 days, and cells were fixed. Fixed cells were stained with anti-PHD2, anti-DAPK and DAPI, and analysed by confocal microscopy. Scale bar, $2.5 \mu \mathrm{m}$. (c) Co-localization of HIF-1 $\alpha$ with PHD2 in Th17 cells. Th17 cells were stained with anti-PHD2, anti-HIF-1 $\alpha$ and DAPI, and analysed by confocal microscopy. Scale bar, $2.5 \mu \mathrm{m}$. (d) DAPK interacts with the N-terminal domain of PHD2. HEK293T cells were transfected with DAPK-Myc, and the N-terminal (aa 1-180) or C-terminal (aa 181-426) domain of FLAG-PHD2 as indicated. Cell lysates were immunoprecipitated with anti-Myc, and the contents of PHD2 and DAPK were determined. (e) DAPK increases the association of PHD2 with HIF-1 $\alpha$ in vitro. Recombinant GST-HIF- $1 \alpha$ protein was incubated with FLAG-PHD2 in the absence or presence of recombinant DAPK-FLAG proteins in PBS at $4{ }^{\circ} \mathrm{C}$ for $4 \mathrm{~h}$. The GST-HIF- $1 \alpha$ complex was pulled down by anti-GST, and the contents of FLAG-PHD2, GST-HIF-1 $\alpha$ and DAPK-FLAG in the precipitates and incubation mixtures were determined. Data (a-e) are representative of two independent experiments.

suppressive activity was not corrected in Dapk ${ }^{-/-} \mathrm{Hifla}^{-/-}$ iTregs (Supplementary Fig. 11d). Together, these results suggest that DAPK-HIF- $1 \alpha$ interaction contributes little to maintain normal Treg functioning, in contrast to a prominent role of DAPK-HIF- $1 \alpha$ antagonism in Th17 cells.

\section{Discussion}

In this study, we identified a negative role of DAPK in Th17 development. In Dapk ${ }^{-1-}$ T cells, generation of IL-17A, IL-17F, IL-21 and IL-23R were highly elevated. We further found that the levels of ROR $\gamma \mathrm{t}$ and $\mathrm{ROR} \alpha$-the transcription factors dictating IL-17 expression-were elevated in DAPK-deficient Th17 cells; even though activation of the Rorc inducer STAT3 was similar between WT and Dapk ${ }^{-1-} \mathrm{T}$ cells (Fig. 2i; Supplementary Fig. $5 \mathrm{~g}$ ). Instead, increases in the expression of ROR $\gamma \mathrm{t}$ and ROR $\alpha$ could be partly attributed to elevated levels of HIF- $1 \alpha$ protein. In addition, phosphorylation of mTOR, p70 S6 kinase, 4E-BP1 and ribosomal S6 were comparable between WT and Dapk ${ }^{-1-}$ Th17 cells (Supplementary Fig. 7), suggesting that the increased levels of HIF-1 $\alpha$ in Dapk ${ }^{-1-}$ Th17 cells are not caused by increased mTOR signalling. We further found that DAPK promoted the destabilization of HIF- $1 \alpha$ protein in a proteasome-dependent manner (Fig. 3).

DAPK expression is induced by TGF- $\beta$ (ref. 43), which is commonly used for Th17 differentiation ${ }^{10,11}$. This may partly explain why DAPK levels were higher in Th17 cells than Th1 cells (Fig. 2a). The lower DAPK expression in Th1 cells likely correlated with the weak effect of DAPK deficiency in Th1 cells. Even though naive Dapk ${ }^{-/-} \mathrm{T}$ cells displayed increased production of IFN- $\gamma$ (Supplementary Fig. 2b), IFN- $\gamma$ expression was not enhanced in re-stimulated DAPK-deficient $\mathrm{T}$ cells, including $\mathrm{T}$ cells optimized for Th0 and Th1 differentiation (Supplementary Figs $2 \mathrm{~d}$ and $5 \mathrm{~d}$ ). In addition, IFN- $\gamma$ production was comparable in MOG-primed T cells from WT and Dapk ${ }^{-1-}$ mice (Fig. 1e). Similarly, transgenic expression of DAPK did not affect Th1 development (Supplementary Fig. 5f).

DAPK deficiency led to enhanced sensitivity to EAE induction (Fig. 1a-c). We found that the ratio of IL-17-expressing cells to IFN- $\gamma$-expressing cells was significantly increased in spinal cords from Dapk ${ }^{-1-}$ mice during peak EAE induction (Supplementary Fig. 4), suggesting enhanced spinal cord infiltration of Dapk ${ }^{-/}$Th17 cells. We also observed that transfer of Dapk $k^{-7}-2 \mathrm{D} 2$ Th17 cells induced highly exacerbated EAE in comparison to WT Th17 cells (Fig. 1f). DAPK-deficient Th17 cells thus displayed increased encephalitogenic activity relative to WT Th17 cells. In contrast, EAE induction by Dapk $k^{-1-}$ 2D2 Th1 cells was similar to that induced by WT 2D2 Th1 cells (Fig. 1g). Therefore, DAPK deficiency correlates with preferential induction of pathogenic Th17.

We have previously shown that DAPK specifically suppresses TCR-induced NF- $\kappa B$ activation ${ }^{42}$, as confirmed here by the elevated RelA nuclear translocation in Dapk-/- $\mathrm{T}$ cells (Supplementary Fig. 2e). NF- $\mathrm{BB}$ activation in T cells is required for the generation of autoimmune encephalomyelitis; mice deficient in NF- $\kappa \mathrm{B} 1$ (p50) are resistant to the induction of $\mathrm{EAE}^{50}$, whereas $\mathrm{PKC} \theta$ deficiency prevents $\mathrm{T}$-cell activation and 

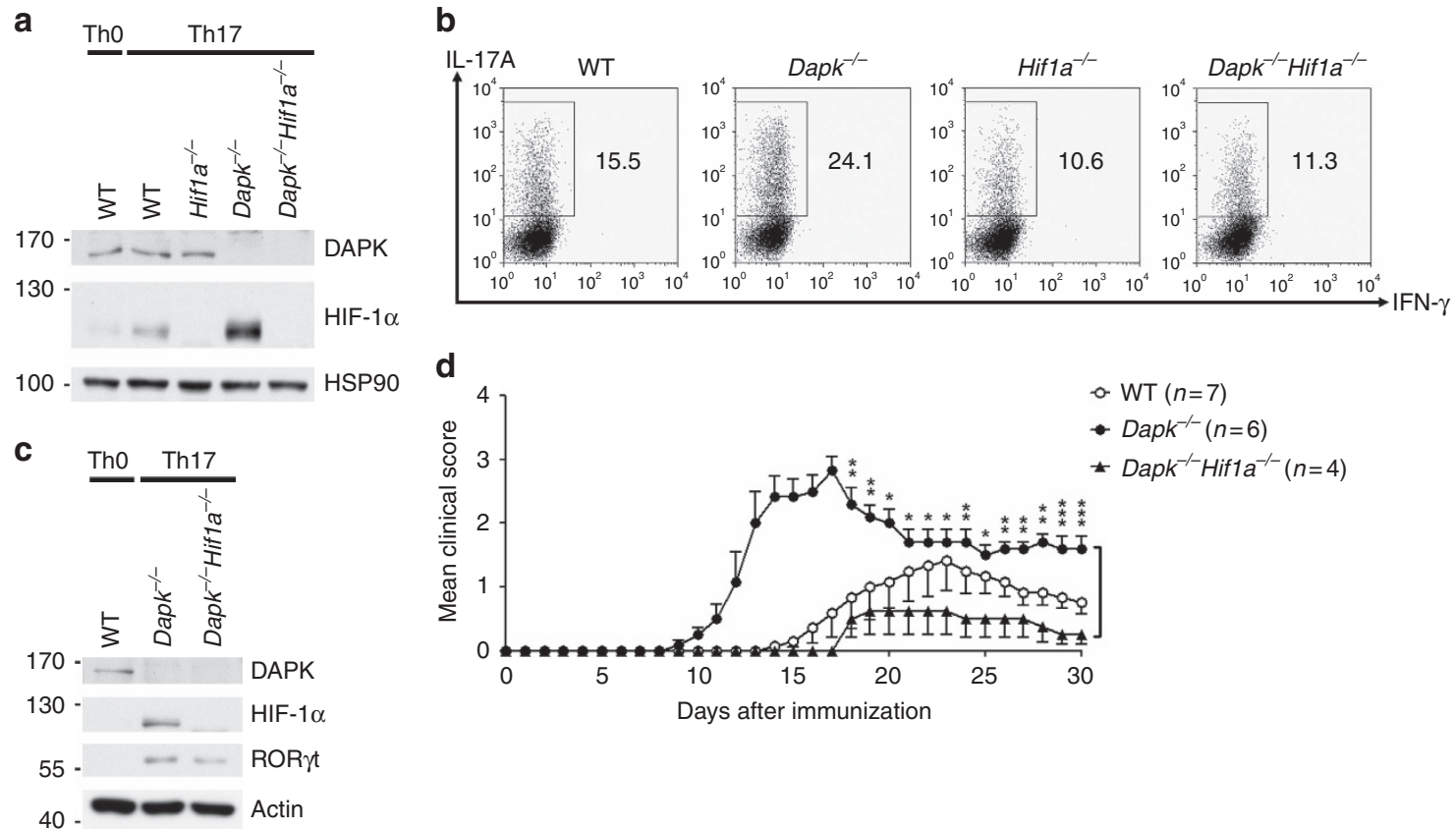

Figure 7 | HIF-1 $\alpha$-knockout prevents excess Th17 differentiation in Dapk ${ }^{-/-}$T cells. Naive CD4 ${ }^{+}$T cells from WT, Dapk ${ }^{-/-}$, Hifla $^{-/-}$and

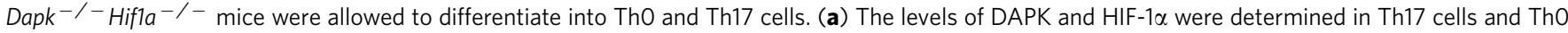
cells after 3 days of differentiation. (b,c) HIF-1 $\alpha$ deficiency reduces the excess Th17 differentiation in Dapk-/- T cells. TPA/A23187-stimulated production of IL-17A and IFN- $\gamma$ was examined in Th17 cells after 5 days of differentiation (b), and the contents of HIF- $1 \alpha$ and ROR $\gamma \mathrm{t}$ were determined (c). Data are representative of three $(\mathbf{b})$ or two $(\mathbf{a}, \mathbf{c})$ independent experiments. (d) HIF-1 $\alpha$ deficiency prevents exacerbated EAE generation in Dapk $-/-$ mice. EAE was induced in WT, Dapk ${ }^{-/-}$, Hif1a ${ }^{-/-}$and Dapk ${ }^{-/-}$Hifla $^{-/-}$mice as in Fig. 1a. Mice were monitored for clinical signs of paralysis. Values are mean \pm s.e.m., ${ }^{\star} P<0.05,{ }^{\star \star} P<0.01,{ }^{\star \star \star} P<0.001$ for unpaired $t$-test.

the pathogenesis of $\mathrm{EAE}^{51}$. NF- $\mathrm{KB}$ has been shown to directly activate the Hifla promoter ${ }^{52}$. In the present study, we found that induction of Hifla transcripts during Th17 differentiation was not affected by Dapk deficiency (Fig. 3c), indicating that enhanced NF- $\kappa \mathrm{B}$ activation in Dapk ${ }^{-/}$T cells did not lead to a further increase in Hifla expression. We speculate that the levels of NF- $\kappa \mathrm{B}$ activation in WT T cells were already sufficient for optimal transcriptional activation of Hifla mRNA.

A previous study of DRAK2 showed that deletion of the gene Stk17b2, which encodes DRAK2, results in complete resistance to EAE induction ${ }^{35}$. DRAK2 knockout is accompanied by increased T-cell activation, similar to Dapk-deficient T cells ${ }^{35}$. However, TCR-induced NF- $\kappa \mathrm{B}$ activation is selectively enhanced in Dapk ${ }^{-1-}$ T cells (Supplementary Fig. 2e), but is attenuated in DRAK2-null T cells $s^{35}$. In addition, DRAK2 consists only of a catalytic domain, lacking the cytoskeleton-binding domain ${ }^{33}$ by which DAPK interacts with HIF- $1 \alpha$ (Fig. $4 \mathrm{~h}$ ). We also found that a DAPK kinase domain fragment was not efficient in promoting HIF-1 $\alpha$ degradation (Supplementary Fig. 9b). It is likely that the different roles in EAE induction of DAPK and DRAK2 could be partly attributed to their differential effects on NF- $\kappa B$ activation and HIF- $1 \alpha$ downregulation.

A novel finding in the present study is that DAPK interacts with HIF- $1 \alpha$ and promotes the degradation of HIF- $1 \alpha$ in T cells. We reveal that, in contrast to the predominant nuclear localization of HIF- $1 \alpha$ in HeLa cells, HIF- $1 \alpha$ protein was present in both the cytoplasm and nucleus of $\mathrm{T}$ cells (Fig. 4a-f). The cytosolic location of HIF- $1 \alpha$ protein permits direct interaction with, and subsequent destabilization by, DAPK. Therefore, DAPK exhibits an additional ability to regulate HIF- $1 \alpha$ protein in T cells by its ability to associate with HIF- $1 \alpha$. We further show that DAPK increased the proline hydroxylation of HIF- $1 \alpha$ protein (Fig. $5 c, d$ ), and HIF-1 $\alpha$ proteins lacking the hydroxylation sites were resistant to DAPK-induced degradation (Fig. 5a,e). Knockdown of PHD2 also eliminated the ability of DAPK to downregulate HIF- $1 \alpha$ (Fig. $5 \mathrm{~g}$ ), suggesting that the binding of DAPK to HIF- $1 \alpha$ protein leads to proline hydroxylation of HIF- $1 \alpha$ and subsequent HIF- $1 \alpha$ ubiquitination by VHL.

HIF- $1 \alpha$ is pivotal for Th17 differentiation. The specific downregulation of HIF- $1 \alpha$ protein by DAPK leads to preferential enhancement of Th17 development in the absence of DAPK-null $\mathrm{T}$ cells. This is further supported by the fact that additional HIF- $1 \alpha$ knockout eliminated the excess Th17 differentiation and encephalitogenic activity of Dapk $k^{-1-}$ T cells (Fig. 7). HIF-1 $\alpha$ protein is also known to promote Foxp3 degradation and negatively regulates Treg differentiation ${ }^{27,49}$. Despite that differentiation and functioning of iTreg from Dapk ${ }^{-I-} \mathrm{T}$ cells were impaired (Supplementary Fig. 8c,d), knockout of HIF-1 $\alpha$ did not restore functioning of Dapk $k^{-1-}$ iTregs (Supplementary Fig. 11d), suggesting a minor role of DAPK-HIF- $1 \alpha$ antagonism in Treg cells. Therefore, the ability of DAPK to inhibit HIF- $1 \alpha$ predominantly regulates Th17 cells, and impaired Treg function do not seem to contribute to the enhanced Th17 development and severe EAE disease observed in Dapk ${ }^{-1}$ mice. Why Th17 and Tregs display different susceptibility to regulation by the DAPK-HIF-1 $\alpha$ interaction is currently being investigated.

Recent studies have revealed that hypoxia promotes the expression of miR-103/107 that target DAPK for downregulation in cancer cells $s^{53}$. HIF-1 $\alpha$ induces the expression of KLHL20, which coordinates with $\mathrm{Cul} 3$ for ubiquitination and proteasome degradation of DAPK in several cancer cell lines ${ }^{54,55}$. Together with the results from the present study, we propose a mutual antagonism between HIF- $1 \alpha$ and DAPK. We suggest that the continuous cross-interaction between HIF- $1 \alpha$ and DAPK, modulated by specific environmental cues, may determine the patho-physiological status of Th17 cells. 
DAPK is a tumour suppressor known to be downregulated in many types of cancers ${ }^{36-41}$. Our results illustrate that DAPK is not only a tumour suppressor, but also plays a role in the prevention of Th17-mediated autoimmune diseases like EAE. DAPK suppresses tumour formation and metastasis through its promotion of apoptosis, induction of autophagy and regulation of cell motility ${ }^{56}$. In the present study, we have demonstrated that DAPK inhibits EAE development by inducing HIF- $1 \alpha$ degradation and inhibiting pro-inflammatory Th17 cell differentiation. Notably, HIF-1 $\alpha$ is also known for its prominent role in tumorigenesis, with levels of HIF-1 $\alpha$ correlating with poor prognoses for various cancer types ${ }^{18,19}$. Even though HIF- $1 \alpha$ is exclusively localized in the nucleus of most cancer cells, it will be interesting to examine whether the ability of DAPK to promote HIF- $1 \alpha$ degradation in the cytoplasm also contributes to the tumour suppressing function of DAPK in selective cancer types. We found that HIF-1 $\alpha$ was present in the cytoplasm of T-cell leukaemia Jurkat cells and was subjected to DAPK regulation (Figs $4 \mathrm{e}$ and 5e), suggesting that DAPK likely exhibits a tumour suppressor effect in $\mathrm{T}$ leukaemia cells by directly binding to the cytosolic HIF- $1 \alpha$ to prompt HIF- $1 \alpha$ downregulation.

Th17 cells contribute to autoimmune diseases-including multiple sclerosis, rheumatoid arthritis, inflammatory bowel diseases, psoriasis and autoimmune diabetes ${ }^{1-3}$, and Th17 is a target for immunotherapy in these inflammatory diseases. In addition to promoting Th17 differentiation, HIF- $1 \alpha$ contributes to the inflammatory activities of different innate immune cells including macrophages and neutrophils ${ }^{22}$. Therefore, targeted HIF- $1 \alpha$ degradation by DAPK upregulation is a potential novel approach in the treatment of Th17-associated inflammatory diseases.

The critical role of HIF- $1 \alpha$ in carcinogenesis and metastases has led to the identification of drugs that inhibit HIF- $1 \alpha$ (refs $18,19,21,31,32$ ). Conceivably, HIF- $1 \alpha$ inhibitors are also potential therapeutic agents for HIF- $1 \alpha$-mediated diseasesincluding pulmonary arterial hypertension, hereditary erythrocytosis, obstructive sleep apnea, ocular neovascularization and traumatic shock ${ }^{19,20}$-as well as Th17-mediated inflammatory diseases. However, HIF- $1 \alpha$ is critical for oxygen homoeostasis, and is protective in coronary artery disease, peripheral artery disease, wound healing, colitis and organ transplantation rejection ${ }^{19-21}$. Thus, the therapeutic benefits of HIF- $1 \alpha$ inhibitors are expected to be offset by the loss of HIF-1 $\alpha$ mediated protective responses. In the present study, we used Th17 as an example to demonstrate an alternative approach to downregulating HIF- $1 \alpha$. The cytoplasmic presence of HIF- $1 \alpha$ permits its interaction with DAPK in the cytosol of $\mathrm{T}$ cells, leading to HIF-1 $\alpha$ downregulation. DAPK-induced cytosolic HIF- $1 \alpha$ degradation presumably does not operate in cells exhibiting exclusively nuclear HIF- $1 \alpha$, leaving the HIF- $1 \alpha$ in those cells unaffected. Compounds that activate DAPK have been identified ${ }^{41}$, and further improvements in the specificity of drugs for DAPK induction may lead to reagents capable of effectively downregulating HIF- $1 \alpha$ in DAPK-dependent processes. These drugs could potentially be used for treatment of Th17-mediated inflammatory diseases and T-cell leukaemia. Future investigations will help validate the therapeutic approach of inhibiting HIF- $1 \alpha$ pathogenic activity in $\mathrm{T}$ cells through DAPK upregulation, without affecting the HIF- $1 \alpha$ in other cells.

\section{Methods}

Reagents. Calcium ionophore (A23187), phorbol 12-myristate 13-acetate (TPA), MG132, chloroquine, ammonium chloride $\left(\mathrm{NH}_{4} \mathrm{Cl}\right)$, leupeptin, cycloheximide (CHX), DFX, anti-DAPK (D2178, DAPK-55, western blot (WB) 1:1,000, immunofluorescence (IF) 1:50), anti-HA (H3633, HA-7, WB 1:1,000, immunoprecipitation (IP) $1 \mu \mathrm{g}$ per test), and anti-FLAG (F1804, M2, WB 1:1,000, IF 1:400) were purchased from Sigma (St Louis, MO, USA). Anti-p70S6K (sc-230, C-18, WB 1:1,000), anti-GAPDH (sc-32233, 6C5, WB 1:10,000), anti-HDAC2 (sc-55541, B-2, WB 1:500) and anti-p65 (sc-372G, C-20, WB 1:1,000) were obtained from Santa Cruz Biotech (Santa Cruz, CA, USA). Anti-ROR $\gamma \mathrm{t}$ (14-6981, B2D, WB 1:1,000), anti-CD4-PE-Cy7 (25-0041, GK1.5, flow cytometry (FCM) 1:100), anti-CD62L-APC (17-0621, MEL-14, FCM 1:100), recombinant mouse IL-6 (14-8061) and IL-23 (14-8231), anti-CD69-PE (12-0691, H1.2F3, FCM 1:100), anti-Foxp3-APC (50-5773, FJK-16s, FCM 1:100), mouse IL-2 and mouse IFN- $\gamma$ ELISA kit were purchased from eBioscience (San Diego, CA, USA). STAT3 antibody (GTX15523, WB 1:1,000) was obtained from GeneTex (Irving, CA, USA) Anti-phospho STAT3 ${ }^{\mathrm{Y} 705}$ (9131, WB 1:1,000), anti-phospho mTOR $^{\text {S2448 }}$ (2971, WB 1:1,000), anti-phospho p70S6K ${ }^{\mathrm{T} 389}$ (9205, WB 1:1,000), anti-phospho 4E$\mathrm{BP1}^{\mathrm{T} 70}$ (9455, WB 1:1,000), Alexa 647-conjugated anti-S6 ${ }^{\mathrm{S} 235 / 236}$ (4851, D57.2.2E, FCM 1:100), Alexa 647-conjugated anti-S6 ${ }^{\text {S240/244 }}$ (5044, D68F8, FCM 1:100), anti-mTOR (2972, WB 1:1,000), anti-4E-BP1 (9452, WB 1:1,000), anti-PHD2 (4835, D31E11, WB 1:1,000, IF 1:50), anti-Myc (2276, 9B11, WB 1:1,000, IP $1 \mu \mathrm{g}$ per test), and anti-hydroxy HIF-1 $\alpha^{\mathrm{P} 564}(3434, \mathrm{D} 43 \mathrm{~B} 5$, WB 1:1,000) were purchased from Cell Signaling Technology (Danvers, MA, USA). Anti-actin (MAB1501, C4, WB 1:6,000) and anti-tubulin (05-661, AA2, WB 1:6,000) were purchased from Merck Millipore (Billerica, MA, USA). Anti- mouse HIF-1 $\alpha$ (10006421, WB 1:1,000, IF 1:100) was purchased from Cayman Chemicals (Ann Arbor, MI, USA) Anti-human HIF- $1 \alpha(610959,54 /$ HIF- $1 \alpha$, WB 1:500, IF 1:100), and anti-HSP90 (610419, 68/Hsp90, WB 1:4,000) were obtained from BD-Biosciences (Franklin Lakes, NJ, USA). Anti-CD4-FITC (100501, RM4-5, FCM 1:100), anti-CD8a-PE (100708, 53-6.7, FCM 1:100), anti-CD44-FITC (103006, IM7, FCM 1:100), anti-IL17A-PE (506904, TC11-18H10.1, FCM 1:100), anti-TCR $\beta$-FITC (109206, H57-597, FCM 1:100), anti-CD25-PE (102008, PC61, FCM 1:100), anti-IFN- $\gamma$ APC (505810, XMG1.2, FCM 1:100), anti-IFN- $\gamma$ (507801, DB-1, IF 1:200), LEAF purified anti-mouse IFN- $\gamma\left(505707, \mathrm{R} 4-6 \mathrm{~A} 2\right.$, cell culture $5 \mu \mathrm{g} \mathrm{ml}^{-1}$ ) and LEAF purified anti-mouse IL-4 $\left(504115,11 \mathrm{~B} 11\right.$, cell culture $\left.5 \mu \mathrm{g} \mathrm{ml}^{-1}\right)$ were purchased from BioLegend (San Diego, CA, USA). Anti-PHD1 (ab108980, EPR2745, WB 1:1,000) and anti-IL-17 (ab91649, IF 1:100) were purchased from Abcam (Cambridge, UK). Anti-mouse CD3 (2C11), anti-mouse CD28 (37.51), anti-mouse IL-2, and anti-mouse CD4 (RL172.4) were purified in our laboratory. Recombinant mouse IL-12 and IL-21, mouse IL-17A ELISA kit, and mouse IL-4 ELISA kit were purchased from R\&D (Minneapolis, MN, USA). Recombinant mouse IL-2 and human TGF- $\beta$ were purchased from PeproTech (Rocky Hill, NJ, USA). Anti-HIF$1 \alpha$ (A300-286A, IP $1 \mu \mathrm{g}$ per test) was purchased from Bethyl Laboratories (Montgomery, TX, USA). Mouse anti-Lamin B1 (33-2000, L-5, WB 1:1,000), Alexa Flour488-labelled goat anti-mouse IgG (A11001, IF 1:500), Alexa Flour555-labelled goat anti-mouse IgG (A21422, IF 1:500), Alexa Flour488-labelled goat anti-rabbit IgG (A11034, IF 1:500) and Alexa Flour555-labelled goat anti-rabbit IgG (A21428, IF 1:500) were purchased from Thermo Fisher Scientific (Waltham, MA, USA). siRNA control (siCtrl), siRNAs specific for PHD2 (EGLN1 siRNA SMARTpool) and for human DAPK (siDAPK) were purchased from GE Dharmacon (Lafayette, CO, USA). The sequence of siDAPK is: UCU GGG AAG CGG AGC UGA AUU.

Cell cultures. HEK293T (ATCC CRL-3216), HeLa (ATCC CCL-2) and Jurkat T lymphoma (clone E6-1, ATCC TIB-152) were obtained from ATCC. Cell lines were examined for mycoplasma contamination using Mycoplasma Detection Kit (R\&D). Normal T cells and Jurkat cells were cultured in RPMI-1640 medium supplemented with $10 \%$ fetal calf serum (Invitrogen Life Technology), $10 \mathrm{mM}$ glutamine, $100 \mathrm{U} \mathrm{ml}^{-1}$ penicillin, $100 \mu \mathrm{g} \mathrm{ml}^{-1}$ streptomycin, and $50 \mu \mathrm{M} \mathrm{2-ME}$ (complete RPMI medium). HEK293T and HeLa cells were cultured in DMEM medium with the same supplements as in complete RPMI medium. For hypoxia $\left(1 \% \mathrm{O}_{2}\right)$ experiments, $\mathrm{T}$ cells were cultured in the cell incubator containing an oxygen controller ProOx-110 (BioSpherix) using gas of $5 \% \mathrm{CO}_{2}$ and $95 \% \mathrm{~N}_{2}$ to reduce the oxygen content. Expression of DAPK or its mutants was performed by transfection of T cells with DAPK, [K42A]DAPK, or [ $\triangle \mathrm{CAM}] \mathrm{DAPK}$ through electroporation using the MP-100 system (Life Technologies).

Mice. Production of Dapk ${ }^{-1-}$ mice ${ }^{44}$ and p37.1-[ $\left.\triangle \mathrm{CAM}\right]$ DAPK-transgenic mice $^{42}$ (both in a C57BL/6 background) were previously described. B6.129Hifla $a^{\text {tm } 3 R s j o / J}$ (Hiflafff) mice ${ }^{57}$, Rag1 ${ }^{-1-}$ mice (in C57BL/6 background), and C57BL/6-Tg(Tcra2D2, Tcrb2D2)1Kuch/J (2D2 TCR $\left.{ }^{\mathrm{MOG}}\right)$ transgenic mice ${ }^{58}$ were obtained from Jackson Laboratories (Bar Harbor, ME, USA). Cd4-Cre mice (in C57BL/6 background) were purchased from Taconic Farms (Hudson, NY, USA). Mice were maintained in the SPF mouse facility of the Institute of Molecular Biology, Academia Sinica. All mouse experiments were performed using 8-16-week-old mice. For in vivo experiments, sex-matched male and female mice were used. Donor and recipient mice were also sex-matched in $\mathrm{T}$ cells transfer assay. Because mouse experiments are limited by the availability of the knockout mice and their littermate control, no randomization was used. Mouse experiments were not blinded. All mouse experiments were conducted with approval from the Institutional Animal Care \& Utilization Committee, Academia Sinica.

Induction of T-helper cells and iTregs. Mouse $\mathrm{T}$ cells were isolated from spleen and peripheral lymph nodes by negative selection using an anti-mouse Ig panning 
method. Total $\mathrm{CD} 4{ }^{+} \mathrm{T}$ cells were purified by positive selection using a rat anti-mouse CD4 antibody (RL172.4) panning method. Naive CD4 T cells $\left(\mathrm{CD} 4{ }^{+} \mathrm{CD} 25^{-} \mathrm{CD} 44^{\text {low }} \mathrm{CD} 62 \mathrm{~L}^{\text {high }}\right)$ were then sorted by FACSVantage SE (BD Bioscience). Naive CD4 T cells were then activated by $2 \mu \mathrm{g} \mathrm{ml}^{-1}$ plate-bound anti-CD3 (2C11) plus $1 \mu \mathrm{g} \mathrm{ml}^{-1}$ anti-CD28 (37.51). IL-2 $\left(20 \mathrm{U} \mathrm{ml}^{-1}\right)$ was added for Th0 differentiation; IL-12 $\left(10 \mathrm{ng} \mathrm{ml}^{-1}\right)$, IL-2 $\left(5 \mathrm{ng} \mathrm{ml}^{-1}\right)$ and anti-IL-4 $\left(10 \mu \mathrm{gl}^{-1}\right)$ were added to induce Th1 development; and TGF- $\beta\left(2 \mathrm{ng} \mathrm{ml}^{-1}\right)$, IL-6 $\left(2 \mathrm{ng} \mathrm{ml}^{-1}\right)$, anti-IL-2 $\left(5 \mu \mathrm{g} \mathrm{ml}^{-1}\right)$, anti-IL-4 $\left(5 \mu \mathrm{g} \mathrm{ml}^{-1}\right)$ and anti-IFN- $\gamma$ $\left(5 \mu \mathrm{g} \mathrm{ml}^{-1}\right)$ were added to induce Th17 differentiation. Th17 cells were also induced by replacing IL-6 with IL-21 $\left(100 \mathrm{ng} \mathrm{ml}^{-1}\right)$ in the same mixture. After 3-to-5 days, Th1 and Th17 cells were re-stimulated with anti-CD3/CD28 or TPA/A23187. For intracellular staining, monensin $(2 \mathrm{nM})$ was added $1 \mathrm{~h}$ after activation, and intracellular content of IL-17 and IFN- $\gamma$ was determined after another $3 \mathrm{~h}$. For mRNA expression, cells were harvested $3 \mathrm{~h}$ after TPA/A23187 stimulation and RNA was prepared. For ELISA, cell culture supernatants were collected $24 \mathrm{~h}$ after TPA/A23187 activation. Induced Treg (iTreg) cells were generated from $\mathrm{CD} 4{ }^{+} \mathrm{CD} 25^{-} \mathrm{T}$ cells and activated by IL-2 $\left(20 \mathrm{ng} \mathrm{ml}^{-1}\right)$, TGF- $\beta$ $\left(5 \mathrm{ng} \mathrm{ml}^{-1}\right)$, and plate-bound anti-CD3 $\left(2 \mu \mathrm{g} \mathrm{ml}^{-1}\right)$ plus anti-CD28 $\left(1 \mu \mathrm{g} \mathrm{ml}^{-1}\right)$ for 1-to-5 days.

EAE induction. DAPK $[\triangle \mathrm{CAM}]$-transgenic, DAPK-knockout, and their WT littermate control mice were immunized subcutaneously with $200 \mu \mathrm{g}$ of MOG peptide 35-55 (Kelowna, Taipei, Taiwan) emulsified in CFA containing $400 \mu \mathrm{g}$ Mycobacterium tuberculosis (Sigma), followed by intraperitoneal injection of $200 \mathrm{ng}$ pertussis toxin (List Labs, Campbell, CA, USA) at day 0 and day 2. Mice were monitored daily for clinical signs and then clinically scored by the following criteria: 0 , no syndrome; 1 , limp tail; 1.5 , tail paralysis and waddling gait; 2 , weak tail and partial hind limb paralysis; 2.5 , paralysis of one hind limb; 3, total hind limb paralysis; 3.5 , complete hind limb and partial fore limb paralysis; 4, moribund state; 5 , complete paralysis and death. Numbers of mice used in EAE experiments were based on those used in documented EAE studies ${ }^{27,59-61}$

EAE induced by adoptive transfer of $2 \mathrm{D} 2 \mathrm{~T}$ cells was performed according to the protocol of Jäger et al..$^{59}$. Naive T cells from 2D2 or 2D2 $\mathrm{Dapk}^{-/-}$mice were differentiated into Th17 cells by incubation with $\mathrm{MOG}_{35-55}$ peptide $\left(20 \mu \mathrm{g} \mathrm{ml}^{-1}\right)$, hTGF- $\beta\left(3 \mathrm{ng} \mathrm{ml}^{-1}\right)$, mIL-6 $\left(20 \mathrm{ng} \mathrm{ml}^{-1}\right)$, anti-IL-4 $\left(5 \mu \mathrm{g} \mathrm{ml}^{-1}\right)$, anti-IFN- $\gamma$ $\left(5 \mu \mathrm{g} \mathrm{ml}^{-1}\right)$ and threefold $\gamma$-irradiated T-cell-depleted splenic cells. IL-23 $\left(10 \mathrm{ng} \mathrm{ml}^{-1}\right)$ was added $48 \mathrm{~h}$ after differentiation. Five days after initial Th17 differentiation, Th17 cells were re-stimulated with plate-bound anti-CD3/antiCD28 $\left(2 \mu \mathrm{g} \mathrm{ml}{ }^{-1}\right.$ each $)$ in the absence of exogenous cytokines for $48 \mathrm{~h} .2 \mathrm{D} 2$ or 2D2 Dapk ${ }^{-1-}$ naïve $\mathrm{T}$ cells were differentiated into Th1 by incubation with $\mathrm{MOG}_{35-55}$ peptide $\left(20 \mu \mathrm{g} \mathrm{ml}^{-1}\right)$, mIL-12 $\left(10 \mathrm{ng} \mathrm{ml}^{-1}\right)$, anti-IL-4 $\left(10 \mu \mathrm{g} \mathrm{ml}^{-1}\right)$ and threefold $\gamma$-irradiated T-cell-depleted splenic cells for 5 days. Th17 and Th1 cells were washed three times with cold PBS, and $5 \times 10^{6}$ Th17 cells or $3 \times 10^{6}$ Th1 cells were transferred intravenously into each Rag1 ${ }^{-/-}$mouse. Recipient mice were injected i.p. with $200 \mathrm{ng}$ of pertussis toxin at day 0 and day 2 after $\mathrm{T}$ cells transfer. The classical EAE scores were described as above. The non-classical (atypical) EAE was scored by the following criteria ${ }^{60}: 0$, no syndrome; 1 , head turned slightly (ataxia, no tail paralysis); 2 , head-turn more pronounced; 3 , inability to walk in a straight line; 4, laying on side and rolling continuously unless supported; 5 , death. Half scores were given (i.e., $1.5,2.5$ ) when the clinical phenotype was deemed to lie between two defined criteria.

Histology on spinal cord sections. Mice were perfused with phosphate buffer saline (PBS) followed by $4 \%(\mathrm{v} / \mathrm{v})$ paraformaldehyde (PFA) in PBS. Spinal cords were isolated and fixed with $4 \%(\mathrm{v} / \mathrm{v}) \mathrm{PFA}$ in PBS overnight at $4{ }^{\circ} \mathrm{C}$. Spinal cords were dehydrated with $30 \%$ sucrose in PBS for $48 \mathrm{~h}$ at $4{ }^{\circ} \mathrm{C}$. Spinal cords were embedded in optimal cutting temperature compound and serial cryosections $(30 \mu \mathrm{M}$ thick) were acquired. Tissue sections were stained with hematoxylin \& eosin or luxol fast blue. Images were obtained on a Zeiss Axio Imager Z1 microscope (Jena, Germany) with an objective lens of plan-Apochromat $10 \times / 0.45$ M27 and the camera of Axiocam 506. The channel was TL Brightfield and the depth of focus was at $5.43 \mu \mathrm{M}$.

For staining with anti-IFN $\gamma$ and anti-IL-17, PFA-fixed optimal cutting temperature-embedded sections were pretreated with sodium citrate buffer $\left(\mathrm{pH} 6.0,10 \mathrm{mM}\right.$ sodium citrate, $0.05 \%$ Tween-20) at $55^{\circ} \mathrm{C}$ for $30 \mathrm{~min}$ for antigen retrieval. Sections were washed and permeabilized with $0.3 \%(\mathrm{v} / \mathrm{v})$ Triton X-100 in PBS at room temperature for $30 \mathrm{~min}$. Sections were incubated in blocking buffer (1\% BSA, $0.3 \%$ Triton X-100 in PBS) at room temperature for $30 \mathrm{~min}$. Sections were then incubated with primary antibodies diluted in blocking buffer for $48 \mathrm{~h}$ at $4{ }^{\circ} \mathrm{C}$. The primary antibodies were anti-IL-17 (Abcam, ab91649, 1:100 dilution) and anti-IFN $\gamma$ (BioLegend, DB-1, 1:200 dilution). Sections were washed and incubated with Alexa Flour 488 or 555 secondary antibodies (Invitrogen, 1:500 dilution) at room temperature for $2 \mathrm{~h}$. Samples were then washed and mounted with DAPI Fluoromount-G buffer (SouthernBiotech, Birmingham, AL, USA).

Quantitative PCR. T cells were harvested at the time indicated and total RNA was isolated using Trizol (Invitrogen). cDNAs were prepared and analysed for the expression of the gene of interest by real-time PCR using a SYBR-Green PCR master mix kit (Roche). The expression of each gene was normalized to the expression of $\beta$-actin. The sequences of the primers were: Rorc, forward, $5^{\prime}$-CGG AGT TTT CCT TTG GGTG- $3^{\prime}$ and reverse, $5^{\prime}$-CCG AGG TAT CTC AGT CAC GAA- $3^{\prime}$; Rora, forward, $5^{\prime}$-GAA CAC CTT GCC CAG AAC AT- $3^{\prime}$ and reverse, $5^{\prime}$-AGC TGC CAC ATC ACC TCT CT- $3^{\prime}$; Ill17a, forward, $5^{\prime}$-CTC ACA CGA GGC ACA AG-3' and reverse, 5'-CTC AGC AGC AGC AAC AG-3'; Ill7f, forward, $5^{\prime}$-GGG AAG AAG CAG CCA TTG-3' ${ }^{\prime}$ and reverse, $5^{\prime}$-TCC AGG GGA GGA CAG TT- $3^{\prime}$; Il21, forward, $5^{\prime}$-AAA CTC AAG CCA TCA AAC CC- $3^{\prime}$ and reverse, $5^{\prime}$-GGT GTC CTT TTC TCA TAC GAA TC-3'; Il23r, forward, $5^{\prime}$-GCA GGA AGT ATT TGG TAT GGG $-3^{\prime}$ and reverse, $5^{\prime}$-GAA ATG ATG GAC GCA GAA GG- ${ }^{\prime}$; $A c t b$, forward, $5^{\prime}$-GCC CCC CTG AAC CCT AA- $3^{\prime}$ and reverse, $5^{\prime}$-GAC AGC ACA GCC TGG AT- $3^{\prime}$; Tbx21, forward, $5^{\prime}$-CGT GGA GGT GAA TGA TGG-3' and reverse, $5^{\prime}$-GTG ATC TCT GCG TTC TGG TAG-3'; Ifng, forward, $5^{\prime}$-ATC AGC AAC AAC ATA AGC GT- $3^{\prime}$ and reverse, $5^{\prime}$-GAC CTC AAA CTT GGC AAT ACTC-3'; Hifla, forward, $5^{\prime}$-CGG CGA GAA CGA GAA GAA- $3^{\prime}$ and reverse, 5'-GCA ACT GAT GAG CAA GCT CATA-3'.

Nuclear extract preparation. Cells were harvested and lysed in cytoplasmic extract (CE) buffer (10 mM Tris- $\mathrm{HCl}$ PH7.4, $10 \mathrm{mM} \mathrm{NaCl}$ and $3 \mathrm{mM} \mathrm{MgCl}$ ) containing $0.1 \%$ (primary T cells) or $0.2 \% \mathrm{NP}-40$ (for HeLa cells) for $4 \mathrm{~min}$ on ice. Cell lysates were centrifuged at 5,000 r.p.m. for $3 \mathrm{~min}$ and the supernatants obtained represented cytoplasmic extracts. Pellets were washed and lysed with RIPA buffer (50 mM Tris-HCl pH 7.4, 1\% NP-40, 0.25\% Sodium deoxycholate, $150 \mathrm{mM} \mathrm{NaCl}$ and $1 \mathrm{mM}$ EDTA). The supernatants obtained after centrifuging at 13,200 r.p.m. for $10 \mathrm{~min}$ represented the nuclear extracts.

Western blot. Cell lysates or immunoprecipitates were resolved by SDS-PAGE and were transferred to PVDF membrane (Millipore) using transfer buffer $(30 \mathrm{mM}$ Tris, $250 \mathrm{mM}$ glycine, $1 \mathrm{mM}$ EDTA, $20 \%$ methanol) at $4{ }^{\circ} \mathrm{C}$ for $2 \mathrm{~h}$ at $400 \mathrm{~mA}$. The membrane was treated with block buffer ( $5 \%$ non-fat milk in $0.1 \%$ TBST $(10 \mathrm{mM}$

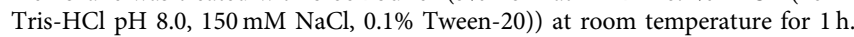
The membrane was then incubated with primary antibodies overnight at $4{ }^{\circ} \mathrm{C}$, followed by horseradish peroxidase-conjugated secondary antibodies in blocking buffer at room temperature for $1.5 \mathrm{~h}$. The membrane was developed using ECL western blotting detection kit (GE Healthcare), and the chemiluminescence detected by X-ray film. Western blot images have been cropped for presentation. Full size images are presented in Supplementary Figs 12-17.

Regulatory T cells. nTregs and iTregs $\left(\mathrm{CD} 4{ }^{+} \mathrm{CD} 25^{+}\right)$were purified by FACS sorting. For in vitro suppressive assays, $\mathrm{CD} 4{ }^{+} \mathrm{CD} 25^{-}$cells (Teff) were placed into round-bottom 96-well plates at $4 \times 10^{4}$ cells per well (for nTreg) or $1 \times 10^{5}$ cells per well (for iTreg), together with anti-CD3 $\left(1 \mu \mathrm{g} \mathrm{ml}^{-1}\right), 3 \times 10^{5} \gamma$-irradiated autologous presenting cells, and different ratios of Treg cells. Cells were incubated for $72 \mathrm{~h}$, and the incorporation of $\left[{ }^{3} \mathrm{H}\right]$ thymidine was determined.

Intracellular localization of DAPK and HIF-1 $\alpha$ /PHD2. Cells were fixed with $4 \%$ $(\mathrm{v} / \mathrm{v})$ PFA in PBS, and permeabilized with $0.1 \%(\mathrm{v} / \mathrm{v})$ Triton X-100. The fixed cells were incubated with blocking buffer (5\% BSA in PBS) at room temperature for $1 \mathrm{~h}$, followed by primary antibodies in blocking buffer overnight at $4{ }^{\circ} \mathrm{C}$. The primary antibodies were anti-FLAG (Sigma, 1:400), anti-Myc (Cell Signaling, 1:400), anti-human HIF-1 $\alpha$ (BD-Biosciences, 1:100), anti-mouse HIF-1 $\alpha$ (Cayman Chemicals, 1:100), anti-DAPK (Sigma, 1:50) and anti-PHD2 (Cell Signaling, 1:50). Cells were washed and incubated with Alexa Flour-labelled secondary antibodies, and were then mounted in DAPI Fluoromount-G buffer (SouthernBiotech, Birmingham, AL, USA). Confocal images were obtained with a Zeiss LSM 780 confocal microscope (Jena, Germany) with an objective lens of Plan-Apochromat $63 \times / 1.4$ Oil DIC M27 at room temperature. DAPI-bound DNA was excited at $405 \mathrm{~nm}$ and collected at 420 to $475 \mathrm{~nm}$. Alexa Fluor 488 dye was excited at $488 \mathrm{~nm}$ and collected at 500 to $550 \mathrm{~nm}$. Alexa Fluor 555 dye was excited at $555 \mathrm{~nm}$ and collected at 568 to $629 \mathrm{~nm}$. The pinhole was at $53 \mu \mathrm{m}$, with a $9.8 \mu \mathrm{m}$ section.

Retroviral infection. DAPK cDNA was cloned into retroviral vector GFP-RV and then transfected into HEK293T cells. Retroviruses were isolated from the culture supernatants of the transfected HEK293T cells by centrifugation at 26,000 r.p.m. for $2 \mathrm{~h}$ at $4{ }^{\circ} \mathrm{C}$ on a Beckman SW28 rotor. The viruses were resuspended in PBS containing $5 \% \mathrm{BSA}$ overnight at $4{ }^{\circ} \mathrm{C}$ and stored at $-80^{\circ} \mathrm{C}$. Purified WT CD4 ${ }^{+}$ T cells were activated with plate-bound anti-CD3 $\left(2 \mu \mathrm{g} \mathrm{ml}^{-1}\right)$ and anti-CD28 $\left(1 \mu \mathrm{g} \mathrm{ml}^{-1}\right)$ with the addition of IL-2 $\left(100 \mathrm{U} \mathrm{ml}^{-1}\right)$ for $48 \mathrm{~h}$. Activated T cells were infected with retrovirus in the presence of $8 \mu \mathrm{g} \mathrm{ml}^{-1}$ polybrene by spinning at 2,000 r.p.m. for $1 \mathrm{~h}$ at room temperature. Infected T cells were cultured in complete RPMI medium with IL-2 $\left(100 \mathrm{U} \mathrm{ml}^{-1}\right)$ for $48 \mathrm{~h}$. GFP ${ }^{+}$cells were sorted by FACSVantage SE, and were cultured in complete RPMI medium plus IL-2 $\left(100 \mathrm{U} \mathrm{ml}^{-1}\right)$ for 2 days before hypoxic treatment.

In vitro binding assays. pGEX-4T3-HIF- $1 \alpha$ (GST-HIF- $1 \alpha$ ) was transformed in BL21 (DE3) Escherichia coli, and recombinant GST-HIF-1 $\alpha$ fusion proteins purified on a glutathione Sepharose 4B column. RK5F-DAPK (DAPK-FLAG) and pcDNA4-PHD2 (FLAG-PHD2) were transfected into HEK293T cells. Transfected 
cells were collected and lysed with WCE buffer $(25 \mathrm{mM}$ pH 7.7 HEPEs, $300 \mathrm{mM}$ $\mathrm{NaCl}, 0.1 \%$ Triton X-100, $1.5 \mathrm{mM} \mathrm{MgCl}_{2}, 0.2 \mathrm{mM}$ EDTA, $0.1 \mathrm{mM} \mathrm{Na}_{3} \mathrm{VO} 4,50 \mathrm{mM}$ $\mathrm{NaF}$ and $0.5 \mathrm{mM}$ DTT). Recombinant FLAG fusion proteins were purified with anti-FLAG M2 agarose. Purified recombinant proteins were incubated in PBS at $4{ }^{\circ} \mathrm{C}$ for $4 \mathrm{~h}$, and then incubated with anti-GST antibody overnight at $4{ }^{\circ} \mathrm{C}$. Samples were incubated with protein $\mathrm{G}$ magnetic beads (GE) at $4^{\circ} \mathrm{C}$ for $1 \mathrm{~h}$. The immune complexes were washed with WCE buffer and examined by western blot.

DAPK kinase assay. DAPK kinase assays were performed as previously described $^{62}$. DAPK proteins were isolated by anti-FLAG from SF21 insect cells and incubated with $5 \mu \mathrm{g}$ GST-HIF-1 $\alpha$ or GST-MLC in kinase reaction buffer (50 mM HEPES pH 7.5, $8 \mathrm{mM} \mathrm{MgCl}_{2}, 2 \mathrm{mM} \mathrm{MnCl}_{2}, 0.5 \mathrm{mM} \mathrm{CaCl}_{2}, 0.1 \mathrm{mg} \mathrm{ml}^{-1}$ bovine serum albumin (BSA), $1 \mu \mathrm{M}$ bovine CaM (Sigma), $50 \mu \mathrm{M}$ ATP, $10 \mu \mathrm{Ci}$ $[\gamma-32 \mathrm{P}] \mathrm{ATP})$ at $25^{\circ} \mathrm{C}$ for $15 \mathrm{~min}$. The reactions were stopped by adding SDS sample buffer, and resolved on SDS-PAGE. The phosphorylation was detected by autoradiography.

Statistics. Our data were randomly collected but were not blinded. We did not exclude any data in this study. Our data mostly meet the assumption of the tests (normal distribution). Microsoft Office Excel and Prism 5.0 (GraphPad software) were used for data analysis. Unpaired two-tailed Student $t$-tests were used to compare results from between two groups. Data were presented as mean with standard deviation (s.d.) or standard error of the mean (s.e.m.), as indicated in the figure legend.

Data availability. All relevant data are available from the authors upon request.

\section{References}

1. Korn, T., Bettelli, E., Oukka, M. \& Kuchroo, V. K. IL-17 and Th17 cells. Annu. Rev. Immunol. 27, 485-517 (2009).

2. Littman, D. R. \& Rudensky, A. Y. Th17 and regulatory T cells in mediating and restraining inflammation. Cell 140, 845-858 (2010).

3. Weaver, C. T., Elson, C. O., Fouser, L. A. \& Kolls, J. K. The Th17 pathway and inflammatory diseases of the intestines, lungs, and skin. Annu. Rev. Pathol. 8, 477-512 (2013).

4. Langrish, C. L. et al. IL-23 drives a pathogenic T cell population that induces autoimmune inflammation. J. Exp. Med. 201, 233-240 (2005).

5. Kroenke, M. A., Carlson, T. J., Andjelkovic, A. V. \& Segal, B. M. IL-12- and IL-23-modulated T cells induce distinct types of EAE based on histology, CNS chemokine profile, and response to cytokine inhibition. J. Exp. Med. 205, 1535-1541 (2008).

6. Stromnes, I. M., Cerretti, L. M., Liggitt, D., Harris, R. A. \& Goverman, J. M. Differential regulation of central nervous system autoimmunity by $\mathrm{T}(\mathrm{H}) 1$ and $\mathrm{T}(\mathrm{H}) 17$ cells. Nat. Med. 14, 337-342 (2008).

7. Harrington, L. E. et al. Interleukin 17-producing CD4 + effector T cells develop via a lineage distinct from the T helper type 1 and 2 lineages. Nat. Immunol. 6, 1123-1132 (2005).

8. Park, H. et al. A distinct lineage of $\mathrm{CD} 4 \mathrm{~T}$ cells regulates tissue inflammation by producing interleukin 17. Nat. Immunol. 6, 1133-1141 (2005).

9. Zepp, J., Wu, L. \& Li, X. IL-17 receptor signaling and T helper 17-mediated autoimmune demyelinating disease. Trends Immunol. 32, 232-239 (2011).

10. Bettelli, E. et al. Reciprocal developmental pathways for the generation of pathogenic effector $\mathrm{T}_{\mathrm{H}} 17$ and regulatory T cells. Nature 441, 235-238 (2006).

11. Mangan, P. R. et al. Transforming growth factor- $\beta$ induces development of the $\mathrm{T}_{\mathrm{H}} 17$ lineage. Nature 441, 231-234 (2006).

12. Ivanov, I. I. et al. The orphan nuclear receptor RORgammat directs the differentiation program of proinflammatory $\mathrm{IL}-17^{+} \mathrm{T}$ helper cells. Cell 126, 1121-1133 (2006).

13. Yang, X. O. et al. STAT3 regulates cytokine-mediated generation of inflammatory helper T cells. J. Biol. Chem. 282, 9358-9363 (2007).

14. Korn, T. et al. IL-21 initiates an alternative pathway to induce proinflammatory $\mathrm{T}_{\mathrm{H}} 17$ cells. Nature 448, 484-487 (2007).

15. Nurieva, R. et al. Essential autocrine regulation by IL-21 in the generation of inflammatory T cells. Nature 448, 480-483 (2007).

16. Gaffen, S. L., Jain, R., Garg, A. V. \& Cua, D. J. The IL-23-IL-17 immune axis: from mechanisms to therapeutic testing. Nat. Rev. Immunol. 14, 585-600 (2014).

17. Yang, X. O. et al. T helper 17 lineage differentiation is programmed by orphan nuclear receptors ROR alpha and ROR gamma. Immunity 28, 29-39 (2008).

18. Keith, B., Johnson, R. S. \& Simon, M. C. HIF $1 \alpha$ and HIF $2 \alpha$ : sibling rivalry in hypoxic tumour growth and progression. Nat. Rev. Cancer 12, 9-22 (2011).

19. Semenza, G. L. Hypoxia-inducible factors in physiology and medicine. Cell 148, 399-408 (2012).

20. Semenza, G. L. Oxygen sensing, hypoxia-inducible factors, and disease pathophysiology. Annu. Rev. Pathol. Mech. Dis. 9, 41-74 (2014).

21. Eltzschig, H. K., Bratton, D. L. \& Golgan, S. P. Targeting hypoxia signalling for the treatment of ischaemic and inflammatory diseases. Nat. Rev. Drug Discov. 13, 852-869 (2014)
22. Palazon, A., Goldrath, A. W., Nizet, V. \& Johnson, R. S. HIF transcription factors, inflammation, and immunity. Immunity 41, 518-528 (2014).

23. Hellwig-Burgel, T., Rutkowski, K., Metzen, E., Fandrey, J. \& Jelkmann, W. Interleukin- $1 \beta$ and tumor necrosis factor- $\alpha$ stimulate DNA binding of hypoxia-inducible factor-1. Blood 94, 1561-1567 (1999).

24. Nakamura, H. et al. TCR engagement increases hypoxia-inducible factor-1 alpha protein synthesis via rapamycin-sensitive pathway under hypoxic conditions in human peripheral T cells. J. Immunol. 174, 7592-7599 (2005).

25. Makino, Y. et al. Hypoxia-inducible factor regulates survival of antigen receptor driven T cells. J. Immunol. 171, 6534-6540 (2003).

26. Shi, L. Z. et al. HIF1 $\alpha$-dependent glycolytic pathway orchestrates a metabolic checkpoint for the differentiation of TH17 and Treg cells. J. Exp. Med. 208, 1367-1376 (2011).

27. Dang, E. V. et al. Control of Th17/Treg balance by hypoxia-inducible factor 1 . Cell 146, 772-784 (2011)

28. Pollizzi, K. N. \& Powell, J. D. Integrating canonical and metabolic signaling programmes in the regulation of $\mathrm{T}$ cell responses. Nat. Rev. Immunol. 14, 435-446 (2014).

29. Kryczek, I. et al. Human TH17 cells are long-lived effector memory cells. Sci. Transl. Med. 3, 104ra100 (2011).

30. Wang, H. et al. Negative regulation of Hifla expression and TH17 differentiation by the hypoxia-regulated microRNA miR-210. Nat. Immunol. 15, 393-401 (2014).

31. Jones, D. T. \& Harris, A. L. Small-molecule inhibitors of the HIF pathway and synthetic lethal interactions. Expert Opin. Ther. Targets 16, 463-480 (2012).

32. Xia, Y., Choi, H. K. \& Lee, K. Recent advances in hypoxia-inducible factor (HIF)-1 inhibitors. Eur. J. Med. Chem. 49, 24-40 (2012).

33. Bialik, S. \& Kimchi, A. The death-associated protein kinases: structure, function, and beyond. Annu. Rev. Biochem. 75, 189-210 (2006).

34. Shiloh, R., Bialik, S. \& Kimchi, A. The DAPK family: a structure-function analysis. Apoptosis 19, 286-297 (2014).

35. McGargill, M. A., Wen, B. G., Walsh, C. M. \& Hedrick, S. M. A deficiency in Drak2 results in a $\mathrm{T}$ cell hypersensitivity and an unexpected resistance to autoimmunity. Immunity 21, 781-791 (2004).

36. Inbal, B. et al. DAP kinase links the control of apoptosis to metastasis. Nature 390, 180-184 (1997).

37. Gozuacik, D. \& Kimchi, A. DAPk protein family and cancer. Autophagy 2, 74-79 (2006)

38. Michie, A. M., McCaig, A. M., Nakagawa, R. \& Vukovic, M. Death-associated protein kinase (DAPK) and signal transduction: regulation in cancer. FEBS $J$. 277, 74-80 (2010).

39. Brognard, J., Zhang, Y. W., Puto, L. A. \& Hunter, T. Cancer associated loss-of-function mutations implicate DAPK3 as a tumor-suppressing kinase. Cancer Res. 71, 3152-3161 (2011).

40. Humbert, M. et al. The tumor suppressor gene DAPK2 is induced by the myeloid transcription factors PU.1 and C/EBP $\alpha$ during granulocytic differentiation but repressed by PML-RAR $\alpha$ in APL. J. Leukoc. Biol. 95, 83-93 (2014).

41. Huang, Y., Chen, L., Guo, L., Hupp, T. R. \& Lin, Y. Evaluating DAPK as a therapeutic target. Apoptosis 19, 371-386 (2014).

42. Chuang, Y. T., Fang, L. W., Lin-Feng, M. H., Chen, R. H. \& Lai, M. Z. The tumor suppressor death associated protein kinase targets to TCR-stimulated NF- $\kappa B$ activation. J. Immunol. 180, 3238-3249 (2008).

43. Jang, C. W. et al. TGF- $\beta$ induces apoptosis through Smad-mediated expression of DAP-kinase. Nat. Cell Biol. 4, 51-58 (2002).

44. Gozuacik, D. et al. DAP-kinase is a mediator of endoplasmic reticulum stress-induced caspase activation and autophagic cell death. Cell Death Differ. 15, 1875-1886 (2008).

45. Ghoreschi, K. et al. Generation of pathogenic $\mathrm{T}_{\mathrm{H}} 17$ cells in the absence of TGF- $\beta$ signalling. Nature 467, 967-971 (2010).

46. Laurence, A. et al. Interleukin-2 signaling via STAT5 constrains T helper 17 cell generation. Immunity 26, 371-381 (2007).

47. Delgoffe, G. M. et al. The mTOR kinase differentially regulates effector and regulatory T cell lineage commitment. Immunity 30, 832-844 (2009).

48. Delgoffe, G. M. et al. The kinase mTOR regulates the differentiation of helper $\mathrm{T}$ cells through the selective activation of signaling by mTORC1 and mTORC2. Nat. Immunol. 12, 295-303 (2011).

49. Darce, J. et al. An N-terminal mutation of the Foxp3 transcription factor alleviates arthritis but exacerbates diabetes. Immunity 36, 731-741 (2012)

50. Hilliard, B., Samoilova, E. B., Liu, T. S., Rostami, A. \& Chen, Y. Experimental autoimmune encephalomyelitis in NF- $\mathrm{KB}$-deficient mice: roles of NF- $\kappa \mathrm{B}$ in the activation and differentiation of autoreactive $\mathrm{T}$ cells. J. Immunol. 163, 2937-2943 (1999).

51. Anderson, K. et al. Mice deficient in PKC theta demonstrate impaired in vivo $\mathrm{T}$ cell activation and protection from $\mathrm{T}$ cell-mediated inflammatory diseases. Autoimmunity 39, 469-478 (2006).

52. Rius, J. et al. NF- $\mathrm{\kappa B}$ links innate immunity to the hypoxic response through transcriptional regulation of HIF-1 $\alpha$. Nature 453, 807-811 (2008). 
53. Chen, H. Y. et al. miR-103/107 promote metastasis of colorectal cancer by targeting the metastasis suppressors DAPK and KLF4. Cancer Res. 72, 3631-3641 (2012).

54. Lee, Y. R. et al. The Cullin 3 substrate adaptor KLHL20 mediates DAPK ubiquitination to control interferon responses. EMBO J. 29, 1748-1761 (2010).

55. Yuan, W. C. et al. A Cullin3-KLHL20 Ubiquitin ligase-dependent pathway targets PML to potentiate HIF-1 signaling and prostate cancer progression. Cancer Cell 20, 214-228 (2011).

56. Chen, H. Y., Lee, Y. R. \& Chen, R. H. The functions and regulations of DAPK in cancer metastasis. Apoptosis 19, 364-370 (2014).

57. Ryan, H. E. et al. Hypoxia-inducible factor-1alpha is a positive factor in solid tumor growth. Cancer Res. 60, 4010-4015 (2000).

58. Bettelli, E. et al. Myelinoligodendrocyte glycoprotein-specific T cell receptor transgenic mice develop spontaneous autoimmune optic neuritis. J. Exp. Med. 197, 1073-1081 (2003).

59. Jäger, A., Dardalhon, V., Sobel, R. A., Bettelli, E. \& Kuchroo, V. K. Th1, Th17, and Th9 effector cells induce experimental autoimmune encephalomyelitis with different pathological phenotypes. J. Immunol. 183, 7169-7177 (2009).

60. Domingues, H. S., Mues, M., Lassmann, H., Wekerle, H. \& Krishnamoorthy, G. Functional and pathogenic differences of Th1 and Th17 cells in experimental autoimmune encephalomyelitis. PLoS ONE 5, e15531 (2010).

61. Rothhammer, V. et al. Th17 lymphocytes traffic to the central nervous system independently of $\alpha 4$ integrin expression during EAE. J. Exp. Med. 208, 2465-2476 (2011).

62. Kuo, J. C., Lin, J. R., Staddon, J. M., Hosoya, H. \& Chen, R. H. Uncoordinated regulation of stress fibers and focal adhesions by DAP kinase. J. Cell Sci. 116, 4777-4790 (2003)

\section{Acknowledgements}

We thank Dr Tzyy-Nan Huang for spinal cord sections, Dr Ching-Yen Tsai of the Transgenic Core, Yamin Lin of the FACS Core and Shu-Hui Huang of the Confocal Core of the Institute of Molecular Biology, Academia Sinica for transgenic mouse generation, cell sorting and confocal microscopy, and Dr John O'Brien for editing the manuscript. This work was supported by grant MOST103-2321-B-001-031 from the Ministry of Science and Technology, and an Academia Sinica Investigator Award from Academia Sinica, Taiwan, R.O.C.

\section{Author contributions}

T.-F.C., Y.-T.C, W.-C.H, P.-Y.C., H.-Y.L., and S.-T.M. performed experiments, T.-S.H. S.-C.M., R.-H.C., A.K. contributed to generation of key materials and constructs, and M.-Z.L. conceived of, designed and supervised the research and wrote the manuscript.

\section{Additional information}

Supplementary Information accompanies this paper at http://www.nature.com/ naturecommunications

Competing financial interests: The authors declare no competing financial interests.

Reprints and permission information is available online at http://npg.nature.com/ reprintsandpermissions/

How to cite this article: Chou, T.-F. et al. Tumour suppressor death-associated protein kinase targets cytoplasmic HIF-1 $\alpha$ for Th17 suppression. Nat. Commun. 7:11904 doi: 10.1038/ncomms11904 (2016).

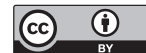

This work is licensed under a Creative Commons Attribution 4.0 International License. The images or other third party material in this article are included in the article's Creative Commons license, unless indicated otherwise in the credit line; if the material is not included under the Creative Commons license, users will need to obtain permission from the license holder to reproduce the material. To view a copy of this license, visit http://creativecommons.org/licenses/by/4.0/ 